\title{
People people: social capital and the labor-market outcomes of underrepresented groups
}

Citation for published version (APA):

Borghans, L., ter Weel, B. J., \& Weinberg, B. (2005). People people: social capital and the labor-market outcomes of underrepresented groups. Researchcentrum voor Onderwijs en Arbeidsmarkt, Faculteit der Economische Wetenschappen. ROA Research Memoranda No. 3E https://doi.org/10.26481/umaror.200503E

Document status and date:

Published: 01/01/2005

DOI:

10.26481/umaror.200503E

Document Version:

Publisher's PDF, also known as Version of record

\section{Please check the document version of this publication:}

- A submitted manuscript is the version of the article upon submission and before peer-review. There can be important differences between the submitted version and the official published version of record.

People interested in the research are advised to contact the author for the final version of the publication, or visit the DOI to the publisher's website.

- The final author version and the galley proof are versions of the publication after peer review.

- The final published version features the final layout of the paper including the volume, issue and page numbers.

Link to publication

\footnotetext{
General rights rights.

- You may freely distribute the URL identifying the publication in the public portal. please follow below link for the End User Agreement:

www.umlib.nl/taverne-license

Take down policy

If you believe that this document breaches copyright please contact us at:

repository@maastrichtuniversity.nl

providing details and we will investigate your claim.
}

Copyright and moral rights for the publications made accessible in the public portal are retained by the authors and/or other copyright owners and it is a condition of accessing publications that users recognise and abide by the legal requirements associated with these

- Users may download and print one copy of any publication from the public portal for the purpose of private study or research.

- You may not further distribute the material or use it for any profit-making activity or commercial gain

If the publication is distributed under the terms of Article $25 \mathrm{fa}$ of the Dutch Copyright Act, indicated by the "Taverne" license above, 


\title{
People People: Social Capital and the Labor-Market Outcomes of Underrepresented Groups
}

\author{
ROA-RM-2005/3E \\ Lex Borghans \\ ROA, Maastricht University \\ l.borghans@roa.unimaas.nl \\ Bas ter Weel \\ MERIT, Maastricht University \\ b.terweel@merit.unimaas.nl \\ Bruce A. Weinberg \\ Department of Economics, Ohio State University \\ weinberg.27@osu.edu
}

* We wish to thank conference and seminar participants at Brown University, De Nederlandsche Bank, the 2004 EALE in Lisbon, IZA, LSE, Maastricht University, the NBER Summer Institute, Notre Dame University, Ohio State University, the 2004 SOLE in San Antonio, and Yale. We are also grateful for comments from David Autor, George Borjas, Charles Brown, Bertrand Candelon, William Dupor, Richard Freeman, Ed Glaeser, John Ham, Masanori Hashimoto, Larry Katz, Hajime Miyazaki, Franz Palm, James Peck, and Bas Straathof. Vasilios Kosteas provided excellent research assistance. Ter Weel acknowledges financial support from the Netherlands Organization for Scientific Research and Weinberg acknowledges support from the National Science Foundation. We are grateful to Francis Green for access to the BSS data, to Alexandra Spitz for help with the BIBB/IAB data, to Arnaud Dupuy for sharing his software to compute breaks, and to David Autor and Michael Handel for sharing the consistent series of occupation classifications for the United States. Part of this work was done while Borghans and Ter Weel were visiting the Department of Economics at Ohio State University and while Weinberg was visiting MERIT and ROA at Maastricht University. We are grateful for their hospitality and support.

\section{Research Centre for Education and the Labour Market}

Faculty of Economics and Business Administration

Maastricht University

Maastricht, February 2005 
ISBN 90-5321-404-6

Sec05.016.doc 


\begin{abstract}
Despite indications that interpersonal interactions are important for understanding individual labor-market outcomes and have become more important over the last decades, there is little analysis by economists. This paper shows that interpersonal interactions are important determinants of labor-market outcomes, including occupations and wages. We show that technological and organizational changes have increased the importance of interpersonal interactions in the workplace. We particularly focus on how the increased importance of interpersonal interactions has affected the labor-market outcomes of underrepresented groups. We show that the acceleration in the rate of increase in the importance of interpersonal interactions between the late 1970s and early 1990s can help explain why women's wages increased more rapidly, while the wages of blacks grew more slowly over these years relative to earlier years.
\end{abstract}

Keywords: Interpersonal Interactions; Wage Level and Structure; Economics of Minorities and Races and Gender; Social Capital

JEL codes: J16; J21; J24; J31 


\section{Introduction}

There are many indications that interpersonal interactions are important for understanding individual outcomes and have become more important over the last decades. Psychologists have been broadening the traditional definition of intelligence to include interpersonal and emotional intelligence [Gardner 1983, Sternberg 1984, and Goleman 1996] and work on interpersonal interactions has entered the economics literature through research done by sociologists and, more recently, economists on social capital [Coleman 1990, Becker and Murphy 2000, and Glaeser, Laibson, and Sacerdote 2002]. Popular perceptions and behavior indicate a widespread belief in the importance of interpersonal interactions and ways to make people like you as determinants of success. ${ }^{1}$ Finally, the shift in employment from manufacturing to services and the diffusion of computer technology and innovative workplace organizations are likely to have increased the returns to interpersonal interactions and the demand for people people at the workplace.

This paper develops a unified model to understand the role of interpersonal interactions in the labor market, including task assignment and wages and investigates these implications empirically. We particularly focus on the impact of interpersonal relationships on the labor-market outcomes of underrepresented groups. It has been widely documented that in the United States women's wages increased rapidly from the late 1970s to the early 1990s, while the wages of blacks grew more slowly over these years than in earlier years. We show that after accounting for long-term trends, the demand for women and blacks has moved in opposite directions and show that an acceleration in the rate at which interpersonal interactions are becoming more important can help explain these trends. ${ }^{2}$

We begin by presenting trends in the importance of interpersonal interactions and the demand for women and blacks. We then explore several data sets from the United States, Britain, and Germany to understand the role of interpersonal interactions in explaining task assignment, wages and labor demand, and the effects of interpersonal interactions on the labor-market positions of women, blacks, and other underrepresented groups. Our approach of modeling interpersonal skills builds on intuitive observations provided by the psychological [Cherniss and Goleman 2001] and management [Carnegie 1936]

\footnotetext{
${ }^{1}$ The massive market for material on How to Win Friends and Influence People, as Dale Carnegie's [Carnegie 1936] classic book is titled, indicates that interpersonal interactions are widely believed to be important. Carnegie's work has sold over 15 million copies and, almost 70 years after it was first published, is ranked $102^{\text {nd }}$ of all books on Amazon.com (on 27 October 2004).

${ }^{2}$ The coding of Hispanics changes over time, and Borjas [1982] has argued that Hispanics are a heterogeneous group. The wages of Hispanic workers decline markedly starting in the late 1970s, while their employment increases. Given these changes, estimates of demand shifts toward Hispanics are highly sensitive to assumptions about elasticities.
} 
literature. If interpersonal tasks are indeed important, it is natural to ask whether they can simply be incorporated into the standard human capital model of individual outcomes as a particular form of human capital or whether understanding the role of interpersonal interactions requires a new model of individual outcomes.

We model interpersonal interactions as a willingness to take costly actions that benefit others ${ }^{3}$ and show that people skills that can be advantageous in one setting can be disadvantageous in others circumstances. ${ }^{4}$ We assume that people vary in their willingness to help others and that jobs are heterogeneous in the importance of helping others. Teaching and nursing emphasize taking actions that benefit others, and people who are most sensitive to others will have an absolute advantage in these jobs and will be allocated to them. In other jobs, such as high-pressure sales, it is a disadvantage to help others, and the least sensitive people will be assigned to those jobs. Effective performance in some jobs often requires making tough decisions regarding others, such as discipline or dismissal. Thus, the returns to interpersonal interactions vary across jobs, and while we find the expected relationship between the supply and demand for interpersonal skills and wages, the overall relationship between interpersonal interactions and wages will be ambiguous.

We test a variety of our model's empirical implications. Our general analysis of interpersonal interactions shows that people who were more sociable when they were young are more likely to be in jobs where interpersonal tasks are more important. We also show that new technologies, including computer technologies, team production, and innovative work practices increase the importance of interpersonal tasks. Turning to the effect of interpersonal skills on the labor-market outcomes of underrepresented groups, psychologists have argued that women place more weight on the effects of their actions on others [Gilligan 2001] and women report being better in performing interpersonal tasks. It is also likely that racial, ethnic, linguistic, and cultural differences interfere with interpersonal interactions, either because members of such minority groups are less able to interact with members of the majority group or because of prejudice on the part of customers and co-workers. Supporting these hypotheses, we find that in occupations where interpersonal tasks become more important, women's

\footnotetext{
See also Borjas [1995] for an analysis of the labor-market developments of immigrants in the 1980s.

${ }^{3}$ This feature of our model is also present in Arrow [1972] who argues that every commercial transaction, especially those conducted over time, has an element of trust. In that way social interrelatedness substitutes for formal or legal rules.

${ }^{4}$ Earnings are non-decreasing in human capital - at worst a particular type of human capital is irrelevant - but interpersonal interactions raise productivity in some tasks while lowering it in others. For this reason, the term "people skills" is a bit of a misnomer. A better term might be interpersonal styles or characteristics.
} 
share of employment is higher, but the share of blacks (especially black men) and other racial, ethnic, cultural, and linguistic minorities is lower. Using structural breaks, we show that the importance of interpersonal tasks increased particularly rapidly between the late 1970s and the early 1990s, and that the rapid increase over this time period can help explain the increase in women's wages relative to men and the stagnation in wages of black workers relative to white workers.

Our empirical work falls into the emerging literature on "soft skills". The returns to beauty found by Hamermesh and Biddle [1994] and Möbius and Rosenblat [2004] and to height among youths by Persico, Postlewaite, and Silverman [2004] support our result of positive labor-market returns to people characteristics, but beauty is only one aspect of interpersonal styles. In addition, Machin et al. [2001] find positive but rather small labor-market returns to sociability variables in Britain, but do not consider the assignment of people with different attitudes to different jobs. For men in the U.S., Kuhn and Weinberger [2002] find positive returns to being a leader in high school, especially in managerial jobs. We look at a broader set of implications than this paper to explain labor-market success. Glaeser et al. [2000] and Glaeser, Laibson and Sacerdote [2002] present suggestive evidence that workers with better interpersonal skills tend to be employed in jobs in which social interactions occur more frequently. They treat people skills as the analogue of cognitive skills in which people invest if there are returns, whereas in our setting interpersonal skills can be detrimental as well. Finally, Glaeser, Sacerdote and Scheinkman [1996] develop an index of social interactions and find that social interactions are important in explaining individual choices in committing different types of crime and schooling choice.

Our theoretical approach is related to a small literature on social incentives in organizations but differs in that we allow firms to directly compensate workers who are sensitive to social pressure. Not allowing for direct compensation, Rotemberg [1994] identifies markedly different, and more restrictive, conditions under which workers benefit from developing altruism toward one another. Kandel and Lazear [1992] show that $1 / N$ problems are a barrier to collective investments in social pressure. With direct compensation workers have an incentive to sensitize themselves to social pressure, making social motivation possible without collective investments. ${ }^{5}$ Ferreira [2002] studies peer pressure and altruism, but he focuses exclusively on teams. Our model also has similarities to Akerlof and Kranton [2003], but we also include worker-side motivation.

\footnotetext{
${ }^{5}$ Foreign automobile manufacturers are known for choosing rural sites for their factories in the United States because workers are perceived to have a stronger work ethic [Levin 1999].
} 
This paper proceeds as follows. Section II outlines trends in the wages, employment, and demand for women and blacks and reviews different explanations from the literature to explain these trends. Section III presents our model of how interpersonal interactions influence labor-market outcomes. Section IV presents the data sources we use. Section V presents general evidence for our model. Section VI studies the effects of interpersonal interactions on the demand for women and blacks and shows that trends in the importance of interpersonal skills can help explain trends in the gender and racial wage gaps. Section VII concludes.

\section{Trends in the Labor-Market Outcomes for Women and Blacks}

This section discusses trends in the labor-market outcomes of women and blacks in the United States (see Altonji and Blank [1999] for a review). Figures I and II show the evolution of the malefemale and the black-white wage gaps and the proportion of the workforce that is female and black in the United States from 1963 to 2002, using data from the March Current Population Surveys (CPS) (see Appendix A2 for details). It has been well documented that women's wages show little growth until the late 1970s, at which point they begin rising rapidly until the mid-1990s. At the same time, women's share of employment increased steadily from 1964 to 2003, with a slight deceleration in the 1990s. ${ }^{6}$ Besides increased labor supply and levels of education there are a number of developments, which can be connected to this development. ${ }^{7}$ Goldin [2004a] shows that changes in the labor-market outcomes for women were rooted in the growth of a wide variety of white-collar jobs, combined with the greater ability of women to hold certain professional jobs. This latter fact is consistent with findings of an increased share of women at the top of the job hierarchy (Bertrand and Hallock [2001] and Goldin

\footnotetext{
${ }^{6}$ Mulligan and Rubinstein [2004] offer an alternative view on the evolution of the gender wage gap. They argue that within-gender wage inequality has changed the composition of the group of women in the labor market and show that, accounting for a growing selection bias over time, the closing of the gender wage gap could be overestimated. Their estimates can, however, not be reconciled with the developments of the importance of interpersonal interactions in the labor market and, at the same time, the movements in the racial wage gap.

${ }^{7}$ Mincer and Polachek [1974] analyze the division of labor in the family using the 1967 National Longitudinal Survey of Work Experience (NLS). They find that differences in labor-market experience, due to interruptions in job careers and the associated loss of skills, can account in large part for the gender wage gap in the 1960s and early 1970s. An early study on female labor supply decisions is Heckman [1974] who estimates the effect of child-care programs on women's labor supply. He finds significant increases in female labor supply and career continuity (see also Meyer and Sullivan [2004]). More recently, Greenwood and Guner [2004] argue that technological progress in the household sector since the late 1940s has reduced the need for labor at home, which increased female labor supply and labormarket opportunities. Juhn and Murphy [1997] investigate whether married women have increased their labor supply in the recent decades to compensate for slowed earnings growth of their husbands and do find no significant increases. Their estimates suggest that the wage effect dominates the cross husband-wife effect for changes in male and female labor supply. A wealth of studies on female labor supply increases identified the increased level of education of women as a major source. In addition, the more labor-market relevant college majors taken by women and their increased enrollment in professional schools are likely to play a major role as well (Goldin [1990], Blau and
} 
[2004b]). The use of the birth-control pill by young women has delayed marriage and motherhood, which opened opportunities for women to progress in the labor market and earn higher wages than before (Goldin and Katz [2002] and Bailey [2004]). In addition, the computerization of the labor market has taken away some of the (physical) disadvantages women had in a non-computerized labor market (Weinberg [2000]). Finally, Black and Brainerd [2004] argue that globalization has increased competition through trade, which has contributed to the relative improvement in female wages in concentrated relative to competitive industries.

From the mid-1990s on however, women's wages are again flat, a development so far unexplained. A recent contribution by Blau and Kahn [2004], using the Michigan PSID, attributes the slowing in the convergence of the gender wage gap to changes in labor-force selectivity, unobserved female characteristics and discrimination, but also to less favorable supply and demand shifts. A number of studies have explained the remaining gender wage gap from gender differences in occupations. For example, Bayard et al. [2003] find that a sizable fraction of the gender wage gap can be attributed to segregation of women into lower-paying occupations, industries, establishments, and occupations within establishments. Blau and Kahn [1997] find for the 1980s in an analysis of shifts in the composition of supply and demand that demand changes favored lower educated women over men but do not consider the stagnation in the gender wage gap afterwards. Blau and Kahn [1997] and Black and Juhn [2000] investigate the labor-market outcomes for high-educated women in the 1980s and 1990s and find that despite the increase in supply, college-educated women entered high-wage professional occupations in response to the recent increase in skill demand. Goldin [2002] also finds a diminishing effect of the importance of gender in employment across occupations, but these studies are not able to explain the break in the gender wage gap since the mid-1990s. ${ }^{8}$ Two recent papers (Xenogiani [2002] and Fortin [2004]) seek to relate women's labor-market outcomes to interpersonal skills, although neither considers racial differences in outcomes.

By contrast, Figure I shows that the racial wage gap closes by 20 percentage points between 1964 and the late 1970s, which is often attributed to the Civil Rights Act of $1964,{ }^{9}$ but is essentially flat

Ferber [1992], and Brown and Corcoran [1997]).

${ }^{8}$ A number of recent studies have linked changes in the gender wage gap to changes in male wage inequality (e.g., Juhn and Kim [1999], Fortin and Lemieux [2000], and Welch [2000]).

${ }^{9}$ For example, Freeman [1973], Smith and Welch [1977; 1984], Brown [1984], Card and Krueger [1993], and Collins [2001] address the timing of the improvements in black workers' relative earnings. Using a variety of research strategies and data sources, they all find evidence consistent with a break in labor-market variables, such as relative employment and wages, in favor of blacks. The improvement in relative school quality in segregated states in the first 
from then until 2003. The employment of blacks fluctuated moderately over the period, increasing somewhat during the 1980s and by more in later years as shown in Figure II. ${ }^{10}$ Juhn, Murphy and Pierce [1991], Bound and Freeman [1992], and Smith [1993] all analyze the stagnation in wages in great detail. ${ }^{11}$ Using information from the CPS, Bound and Freeman [1992] look at the relative labor-market position of young black men. Their findings suggest that increases in the racial wage gap seem to originate from different sources than the overall trend towards increasing wage inequality since the early 1980s. In particular, they attribute the worsening of black labor-market prospects to a variety of sources, which are different for different educational and geographical groups. Among the most prominent sources are the decreased emphasis on affirmative action during the Reagan administration, the decline of inner cities, the shift from manufacturing to services, the decline in union density, and the fall in real minimum wages, which hit young black workers hardest. Cutler and Glaeser [1997] add to this that the increased segregation of blacks worsens their economic and schooling performance, particularly if they live in central cities. ${ }^{12}$ Juhn, Murphy and Pierce [1991], and Smith [1993] attribute the slowdown in the closing of the racial wage gap to slowing education gains, the sharp rise in returns to education in favor of white prime-aged workers, and falling wages at the bottom end of the labor market which hurt low-educated black men severely. ${ }^{13}$

half of the $20^{\text {th }}$ century is also seen as a source of falling racial wage gaps since the 1960 s. For example, Donohue, Heckman and Todd [2002] address the racial wage gap in the period 1910-1960 and find considerable convergence in wages for cohorts born since the late 1930s, which they attribute to increases in schooling quality in the Southern States. Card and Krueger's [1992] findings are consistent with improvements in the relative quality of black schools in the first half of the $20^{\text {th }}$ century. Their estimates suggest that improved quality of schooling is able to explain about 20 percent of the narrowing of the racial wage gap in the period 1960-1980.

${ }^{10}$ There are a number of papers that have studied selection bias in estimating black-white wage gaps. Using U.S. Census data Chandra [2000] reports that labor-market participation among prime-aged black men was considerably lower than the labor-market participation of white men in the period 1940-1990. Neal [2004] measures the black-white wage gap among women using a variety of U.S. data sources and finds that different reas ons for non-participation between black women (often single mothers) and white women (often receiving support from a high-earning spouse) have led to a downward bias in the measured black-white wage gap. A recent paper by Chandra [2003] is concerned with the efficacy of the Civil Rights Act and the development of the racial wage gap in the period thereafter (see also Heckman, Lyons and Todd [2000]). His estimates suggest that selection bias plays a considerable role in understanding racial wage gaps (Donohue and Heckman [1991] provide a review of the effects of the Civil Rights Act on racial differences in the U.S. labor market).

${ }^{11}$ See e.g., Smith and Welch [1989], Jaynes [1990] and Heckman and Donohue [1991] for overviews of the labor-market position of blacks in the United States.

${ }^{12}$ Cutler, Glaeser and Vigdor [1999] find that over the $20^{\text {th }}$ century segregation between blacks and whites has varied over time. They find evidence that the mechanism sustaining segregation has changed from excluding blacks from neighborhoods (mid-century) to decentralized racism, where whites pay more than blacks to live in predominantly white areas (1990s).

${ }^{13}$ See also Juhn [1992]. Neal and Johnson [1996] suggest that racial discrepancies in basic skills due to differences in education and family background are also important factors in explaining the slowdown in the convergence of the racial wage gap. Card and Lemieux [1994] find mixed results for the return to skill. Among females the racial wage gap widened in the early 1980s. For men wage gap declined between 1979 and 1985, which is inconsistent with the rise in 
As indicated, these simple patterns of wages and employment of underrepresented groups are known in the literature and a variety of explanations have been provided for them, but we are not aware of a unified explanation. Unlike most research, which has focused on changes in wages, we focus on the change in labor demand for women and blacks. To estimate trends in the demand for women and blacks, we assume a constant elasticity of substitution (CES) aggregate production function and impute the demand series in employment terms as

$$
D=\ln \left(\frac{w_{G}}{w_{\sim G}}\right)+\varepsilon \ln \left(\frac{e_{G}}{e_{\sim G}}\right),
$$

where $w_{G}\left(e_{G}\right)$ and $w_{\sim G}\left(e_{\sim G}\right)$ denote the wages (employment) of people in group $G$ or other groups $\sim G$. We apply elasticities of substitution of $1,1.75$, and $2.5 .^{14}$ The imputed demand series for women is shown in Figure III: It is relatively flat until the late 1970s, rises rapidly until 1992 and then flattens out again. Figure IV for blacks shows a substantial increase until the late 1970s and a more gradual increase thereafter. There is some indication of acceleration in the demand for black workers in 1990s. In both cases, the size of the imputed demand shift increases with the elasticity assumed in the years when wages for women and blacks were increasing because higher elasticities place more weight on wage changes.

Panel A of Table I provides estimates of structural breaks in the series based on Bai [1997]. We reject the hypothesis of less than two breaks in the demand series for women at all elasticities. Bootstrapped confidence intervals indicate that the demand shift toward women accelerated between 1975 and 1977 (depending on the assumed elasticity) and decelerated in 1992. Taking into account the 95 percent confidence intervals for these break years, the breaks are estimated to be between 1973 and 1978, and 1991 and 1993. The confidence interval for the first break becomes smaller when the assumed elasticity is higher.

The demand shift toward blacks decelerated after 1977 or 1978. For elasticities up to 1.75 we find a second break in 1997, with the confidence interval for the year of the break ranging from 1993 to the end of the period. ${ }^{15}$ When the elasticity equals 2.5 the demand series becomes unstable. We find a

\footnotetext{
the return for skills.

${ }^{14}$ We motivate our use of these values for the elasticities of substitution as follows. Weinberg [2000] estimates an elasticity of substitution between men and women of 2.4. We have estimated the elasticity of the demand for blacks using panel data on the nine Census divisions from 1963 to 2002, by regressing the log employment of blacks relative to non-blacks on the log wage of blacks relative to whites and division and time fixed effects. This regression yields an estimate for the elasticity of substitution of 1.027 with a standard error of .093 .

${ }^{15}$ To guarantee a consistent estimation, break years in the first and last 5 years of the time series are excluded.
} 
second break year in 1983, but when testing for more breaks, other significant breaks can be found too.

Figure V provides some evidence on the increase in the importance of interpersonal tasks in the labor market from 1971 to 2002 . The estimates are averages of tasks in three-digit occupations from the 1977 Dictionary of Occupational Titles (DOT), which are weighted by the fraction of the workforce in each occupation (Appendix A1 provides details about the definition of interpersonal tasks). Thus, these figures give the trend in the importance of interpersonal tasks arising from shifts between three-digit occupations. Insofar as much of the shift in the importance of interpersonal skills occurs within occupation categories, this figure understates the full increase in the importance of interpersonal tasks. It is possible to compare within and between-occupation changes using data from Germany. In those data, we estimate that 95 percent of the increase in the importance of interpersonal skills arises within occupations. Cross-region regressions of within-occupation changes in interpersonal interactions on between occupation changes yield a point estimate of 2.579 (standard error 1.234). Taking these estimate as indications of the relationship between within and between occupation changes, the total increase in interpersonal interactions is likely to be at least 3.6 times between-change and potentially much larger. While caution is required in inferring the exact timing or magnitude of the increased importance of interpersonal skills, the relationships between this series and the demand for women and blacks, suggests that these phenomena are connected.

To provide some indication of types of jobs in which interpersonal interactions are important, Table A3 lists the 25 largest three-digit occupations in the United States and Table A4 lists the 10 largest two-digit occupations in Germany sorted by the importance of interpersonal interactions. Despite the differences between the countries and the differences in the classifications, in both countries interpersonal interactions are particularly important for nurses, teachers, sales workers, and secretaries. Interpersonal interactions are relatively unimportant for machine operators and truck drivers. Table A5 lists the 10 occupations with the largest increases and decreases in the importance of interpersonal skills in the Germany. Most, but not all, of the occupations with increases are the ones in which interpersonal skills were originally important. The ones with declines are those in which interpersonal interactions were not important. Thus, there is some accentuation in the variations in the importance of interpersonal skills.

Looking for breaks in the three series simultaneously (following Bai, Lumsdaine and Stock [1998]) we find breaks in 1977 and $1992 .{ }^{16}$ Panel B of Table I provides estimates of the breaks in the

\footnotetext{
${ }^{16}$ These estimates are based on elasticities of substitution of 1.75 .
} 
series based on these break years. ${ }^{17}$ The estimates indicate that if women's relative wages had remained constant over the period, firms would have increased their relative employment of women by between .9 percent and 2.8 percent more per year between 1977 and 1993 than in the years before 1977 and by 2.4 percent to 4.3 percent more per year than in the years after 1993. The deceleration in the shift in demand toward blacks would lead their relative employment to increase by 1.0 to 3.5 percent less per year after 1977 if their wages had remained constant over the entire period. After 1993 the demand increases by between 1.0 and 1.2 percent per year. Consistent with these findings, the indicator of people skills accelerates in 1977 and decelerates in 1993. We further investigate this link using micro data after providing a general model of interpersonal interactions in the labor market.

\section{Theory}

\section{III.A. General Setting}

A worker holds a job in which he deals with a third party, who may be a client, colleague, patient, pupil, subordinate, or even the firm owner. The worker chooses an action $a \in[0,1]$, higher levels of which benefit the firm. The third party receives benefits of $\theta a$ from the action. In nursing, teaching, and many service jobs, the action the firm desires helps the third party, so $\theta>0$ (if the third party is the firm owner himself $\theta>0$ as well). In other jobs, such as high-pressure sales, the action that benefits the firm is detrimental to the third party, so $\theta<0$. Also supervisory jobs often involve taking actions that are detrimental to a third party, such as deciding whether to hire, dismiss, or discipline a subordinate.

We model interpersonal "skills" in a reduced form manner using altruism. True altruism can arise between people with ongoing relationships. Our formulation can also capture the effect of social pressure arising through networks or repeated interactions, in which people can reward or punish the worker through other people or in the future. ${ }^{18}$ It can also capture the identification of areas of common interest in negotiation in a reduced form manner. ${ }^{19}$ In both cases the third party will use social pressure to make the agent do the thing that raises his utility, which will make the worker behave as if he is altruistic. Let

\footnotetext{
${ }^{17}$ Estimates based on break years one or two years before or after 1977 and 1993 provide similar findings, which shows the robustness of the results.

${ }^{18}$ Social pressure differs from altruism in that the worker may not obtain utility from the effect of his action on the third party. This can be modeled by assuming that after being hired the worker behaves as if he is altruistic, but that he evaluates jobs ex ante based on selfish preferences. While we do not consider this possibility here to simplify the exposition, results for the more general case can be found in Borghans, Ter Weel, and Weinberg [2004a].

${ }^{19}$ One aspect of negotiating is identifying areas of common interest. People who are good in doing so will be able to obtain greater utility for themselves for any given utility of the third party, which can also be captured in the model.
} 
$\alpha\left(x_{W}, x_{F}\right)$ denote the worker's altruism for the third party, which depends on the worker's characteristics, $x_{W}$, and the characteristics of the firm, $x_{F}$, including those of the other workers at the firm and the third parties with whom the worker will interact. (For simplicity, we assume that $x_{W}$ and $x_{F}$ are normalized so that $\alpha\left(x_{W}, x_{F}\right)$ is increasing in both arguments.) The cost of the action to the worker is $c(a)$, where $c^{\prime}(a)>0$ and $c^{\prime \prime}(a)>0$. Initially, we assume that $a$ is observable and that the firm and worker contract over it. The worker's utility is,

$$
U=\ln (w)+\alpha \theta a-c(a) .
$$

Letting $U^{R}\left(x_{W}\right)$ denote the worker's reservation utility, the worker's wage satisfies,

$$
w=\exp \left\{U^{R}-\alpha \theta a+c(a)\right\} .
$$

Firms' profits are $\pi=R(a, \theta)-w$. Here $R(a, \theta)$ denotes revenue, which depends on the worker's action $a$ and the nature of the work given by $\theta$. As indicated, $a$ is normalized so that $R_{a}>0$. In jobs where the worker's job is to help the third party $(\theta>0)$, increases in $\theta$ will likely increase the marginal benefits to the firm from $a$, because as the benefit of the action for the third party increase, the firm itself is presumably rewarded more for high actions, implying $R_{a \theta}>0$. As discussed below, $R_{a \theta}>0$ may not hold at firms where $\theta<0$. The firm sets $a$, taking the worker's reservation utility as given to maximize profits,

$$
\frac{\partial \pi}{\partial a}=R_{a}(a, \theta)-\frac{\partial w}{\partial a}=R_{a}(a, \theta)-\exp \left\{U^{R}-\alpha \theta a+c(a)\right\}\left(c^{\prime}(a)-\alpha \theta\right)=0 .
$$

\section{III.B. Comparative Statics Results}

We begin by considering the case where workers differ in $x_{W}$, but all firms have the same values of $x_{F}$ and $\theta$. We refer to this as the case of internal social pressure. In equilibrium, firms must be indifferent toward changes in $x_{W}$,

$$
\frac{\partial \pi}{\partial x_{W}}=R_{a} \frac{\partial a}{\partial x_{W}}-\frac{\partial w}{\partial x_{W}}=0 \text { so } \frac{\partial w}{\partial x_{W}}=R_{a} \frac{\partial a}{\partial x_{W}} .
$$

The effect on the action, log wage, worker's utility, and firm's profit of an increase in $x_{W}$ are given in Table II. With the exception of profits, which do not vary with $x_{W}$, all of these have the sign of $\theta$. Higher $\alpha$ workers care more about the third party and take a higher action if the action helps the third party, or a lower action, if it hurts the third party. Because in equilibrium firms must be indifferent 
between workers with different values of $x_{W}$, when $\theta>0(\theta<0)$ the higher (lower) action for high $\alpha$ workers raises (lowers) the wage. Higher $\alpha$ workers have higher utilities if $\theta>0(\theta<0){ }^{20}$

We now consider variations in $x_{F}$, again assuming that workers are identical, which we refer to as external social pressure. This case differs from the case where $x_{W}$ varies in that all workers must be indifferent between firms, so that the rents generated by differences in $x_{F}$ accrue to firms, not workers. The effects of differences in $x_{F}$ that increase $\alpha$ are given in Table II. The first two expressions differ from those above for differences in $x_{W}$ by the second terms, which reflect that the rents the firm captures arising from workers receiving more utility from helping the third party at firms where $\alpha$ is higher because of $x_{F}$. Consequently, as shown in the third and fourth rows of the table, $x_{F}$ has no effect on workers' utility, but firms where $\alpha$ is higher because of $x_{F}$ have higher profits, so long as $\theta>0$.

The cases of purely internal and external social pressure are extreme. Usually social pressure arises from the match between a principal, agent, and third party. In this case, one expects the rents to be split between the principal and the agent (or third party). Presumably, people with similar backgrounds will be particularly well paired from the perspective of social pressure, which is consistent with people working for or with people of similar backgrounds [Costa and Kahn 2003]. Thus, increased affluence in a demographic group improves agents' opportunities to work for members of their own group and may increase the demand for difficult to monitor services where social pressure is particularly valuable. An increase in firm owners in an underrepresented group would benefit workers from that group because there is a gain to matching workers with owners, only part of which is obtained by the owner. Our results suggest that homogenous societies will have greater cooperation, which is consistent with studies on differences in social capital between regions and countries [Putnam 1993 and Knack and Keefer 1997] and rates of homeownership, which gives people an incentive to invest in social capital [DiPasquale and Glaeser 1999].

Lastly, we consider the case where all workers are identical but where firms vary in $\theta$. As with changes in $x_{F}$, when all workers are identical, workers must be indifferent toward firms with different values of $\theta$. The effect on the action depends on the sign of $R_{a \theta}$. As indicated, in jobs that involve caring for the third party $(\theta>0)$ such as childcare, firms clearly benefit more from having the worker

\footnotetext{
${ }^{20}$ Hoff and Sen [2003] provide a striking example of the disadvantages of social pressure in developing countries, where they show that successful individuals can be pressured into hiring unqualified kin or tribe members.
} 
taking high actions, so $R_{a \theta}>0$. As can be seen in Table II, in this case, an increase in $\theta$ leads the worker to take a higher action. The worker receives a higher wage as compensation for the additional effort. There is also a compensating differential effect, with high- $\theta$ jobs paying lower wages because they are more desirable. Overall, the relationship between wages and $\theta$ is ambiguous. Higher actions at high $\theta$ firms raise their profits.

In jobs where the worker must take actions that are harmful to the third party $(\theta<0)$, such as high-pressure sales, the benefit to the firm of a high action may be reduced as $\theta$ increases, so $R_{a \theta}<0$. In this case, there is some ambiguity in the effect of $\theta$ on the worker's action, in that at the lowest $\theta$ jobs workers receive considerable disutility from taking high actions, but the firm obtains great benefits. If firms' benefits are sufficiently high in the lowest $\theta$ jobs, we see workers taking very high actions and being compensated for the disutility they obtain from harming the third parties they encounter in the form of higher wages. As above, workers are indifferent between jobs in equilibrium, with rents from changes in $\theta$ affecting profits.

It is worth noting that the model also implies a complementarity between $x_{W}$ or $x_{F}$ and $\theta$. Firms where the worker can directly benefit their third parties the most have the most to gain from generating altruism in their workers.

\section{III.C. Assignment}

This section considers the assignment of heterogeneous workers to heterogeneous jobs. For simplicity, we assume that there are two types of jobs, with $\theta^{L}<\theta^{H}$ and with population shares $\phi^{L}$ and $\phi^{H}$ and two types of workers, with $\alpha^{L}=0<\alpha^{H}$ and with population shares $\omega^{L}$ and $\omega^{H}$. The total number of workers equals the total number of firms. We also assume that revenue and cost are linear in $a$, so $r(a, \theta)=r a$ and $c(a)=c a$.

Under these assumptions, the action, wage, and profit are

$$
\begin{aligned}
& a=\left[\ln \left(\frac{r}{c-\alpha \theta}\right)-U^{R}\right] \frac{1}{c-\alpha \theta}, \\
& w=\frac{r}{c-\alpha \theta},
\end{aligned}
$$

and 


$$
\pi=\left[\ln \left(\frac{r}{c-\alpha \theta}\right)-U^{R}-1\right] \frac{1}{c-\alpha \theta} .
$$

Under these assumptions, $L$-workers earn $w^{L}=\frac{r}{c}$. The mean wage of $H$-workers depends on their assignment to jobs. The $H$-workers have a comparative advantage in $H$-jobs, so if $\omega^{H}<\phi^{H}, H$ workers take $H$-jobs and earn $w^{H}=\frac{r}{c-\alpha^{H} \theta^{H}}$. If $\omega^{H}>\phi^{H}$, mean wages among $H$-workers are

$$
\bar{w}^{H}=\frac{\phi^{H}}{\omega^{H}} \frac{r}{c-\alpha^{H} \theta^{H}}+\frac{\omega^{H}-\phi^{H}}{\omega^{H}} \frac{r}{c-\alpha^{H} \theta^{L}} .
$$

Because $\frac{r}{c-\alpha^{H} \theta^{H}}>\frac{r}{c-\alpha^{H} \theta^{L}}, \bar{w}^{H}$ is increasing in $\frac{\phi^{H}}{\omega^{H}}$.

We test our model's implications for assignment, seeing whether workers with observable characteristics that are correlated with interpersonal skills lead workers to take jobs where people skills are more important. We consider a range of variables that capture interpersonal skills and also demographic characteristics that correlate with effectiveness in interpersonal interactions. ${ }^{21} \mathrm{We}$ also draw on our model's wage implications to determine how shifts in the supply and demand for various groups of workers have affected the wage structure.

\section{III.D. Extensions and Additional Implications}

\section{III.D.1. Imperfect Information}

This section considers the effect of interpersonal relationships in the labor market when the worker's action is unobservable. In fact, we show that interpersonal relations are of particular value when information is imperfect. We now assume that the firm does not observe $a$, but observes a binary signal whose realization is affected by the worker's action. The probability of the high signal is given by $\rho(a)$, where $\rho^{\prime}(a)>0$ and $\rho^{\prime \prime}(a) \leq 0$. The firm conditions the worker's wages on the signal, paying $w_{H}\left(w_{L}\right)$ if the signal is high (low).

The worker chooses $a$ to maximize his expected utility, $E[U]$, given by

$$
\max _{\{a\}} \rho(a) \ln \left(w_{H}\right)+(1-\rho(a)) \ln \left(w_{L}\right)+\alpha \theta a-c(a) .
$$

\footnotetext{
${ }^{21}$ While our model has stark implications for assignment, we expect observed assignment to be more continuous because workers with a given set of observed interpersonal skills will differ in terms of unobserved interpersonal interactions and other skills that affect productivity in various jobs.
} 
The first-order condition for a maximum to the worker's problem is

$$
\rho^{\prime}(a) \ln \left(\frac{w_{H}}{w_{L}}\right)+\alpha \theta-c^{\prime}(a)=0 \text {. }
$$

By applying the implicit function theorem, it is possible to derive results that are analogous to those above for the perfect-information case. Thus, the worker's action is increasing in $\alpha$ if $\theta>0$ and decreasing in $\alpha$ when $\theta<0$. Similarly, increases in $\theta$ raise the worker's action.

With imperfect information, it is possible to derive implications for the pecuniary incentives given to the worker. The strength of pecuniary incentives are reflected by the log wage spread,

$$
\ln \left(\frac{w_{H}}{w_{L}}\right)=\frac{c^{\prime}(a)-\alpha \theta}{\rho^{\prime}(a)} .
$$

First, workers who feel more social pressure to help the third party (either because of $x_{W}$ or $x_{F}$ ) require weaker pecuniary incentives when the action benefits the third party (i.e., $\theta>0$ ), but more when the action hurts the third party in that

$$
\frac{\partial \ln \left(w_{H} / w_{L}\right)}{\partial \alpha}=-\frac{\theta}{\rho^{\prime}(a)} .
$$

Second, firms in which the agent's action has greater benefits for a third party require less pecuniary incentives:

(9) $\quad \frac{\partial \ln \left(w_{H} / w_{L}\right)}{\partial \theta}=-\frac{\alpha}{\rho^{\prime}(a)}<0$.

Thus, social pressure and pecuniary incentives are substitutes, which is consistent with less reliance on incentive pay in countries, such as Japan, where there is greater social pressure in the workplace, and an increased reliance on pecuniary incentives as social incentives have eroded.

As above, the strength of the benefits received by a third party complements the agent's sensitivity to social pressure in reducing reliance on pecuniary incentives:

$$
\frac{\partial^{2} \ln \left(w_{H} / w_{L}\right)}{\partial \alpha \partial \theta}=-\frac{1}{\rho^{\prime}(a)}<0 .
$$

Insofar as wage spread is costly (in the sense of expected wages) to firms, there is a gain from matching sensitive agents to firms where the agent's actions have large benefits for third parties. As shown in Borghans, Ter Weel and Weinberg [2004a], it is possible to obtain assignment results similar to those 
presented above in the imperfect-information context.

Last, the reduction in pecuniary incentives from higher social incentives - from either $\alpha$ or ? - is greater when the outcome provides less information about the action taken by the agent. We show this by considering an increase in $\rho^{\prime}(a)$, which reduces the informativeness of the signal locally. Taking the second derivative of (7) with respect to $\rho^{\prime}(a)$ yields,

$$
\frac{\partial^{2} \ln \left(w_{H} / w_{L}\right)}{\partial \alpha \partial \rho^{\prime}(a)}=\frac{\theta}{\left(\rho^{\prime}(a)\right)^{2}} \text { and } \frac{\partial^{2} \ln \left(w_{H} / w_{L}\right)}{\partial \theta \partial \rho^{\prime}(a)}=\frac{\alpha}{\left(\rho^{\prime}(a)\right)^{2}} \text {. }
$$

When $\theta>0$, both of these expressions are positive. This result explains why it is particularly important to have caring agents in contexts when it is difficult to monitor performance, such as the care for the young or elderly. From the other side, United States Government contracts, which eliminate social pressure for legal reasons, rely more heavily on explicitly provision than private sector contracts (e.g., Marvel and Marvel [2003]).

When information is imperfect and when the agent's action benefits the third party, social pressure serves as a commitment mechanism to ensure that he takes a high level of action. He obtains higher utility from the reduction in wage spread. Rotemberg [1994] argues that when altruism can be observed, when there are strategic complementarities, and when others can make reciprocal changes in altruism, it can be optimal to invest in altruism to maximize selfish utility. With imperfect information, it is possible to show that being subject to social pressure can raise selfish utility without strategic complementarities or reciprocal altruism when firms compete for and compensate these workers. Insofar as workers themselves gain from being subject to social pressure (and firms can determine their sensitivity to it), if workers can invest in their sensitivity to social pressure, those in jobs where $\theta>0$ benefit from making themselves sensitive to social pressure.

Kandel and Lazear [1992] argue that 1/N problems constrain collectively generated social pressure. Our results suggest that there may be little need for collective investments for social motivation to be effective because workers have an incentive to invest on their own.

\section{III.D.2. Additional Implications}

The model indicates that being subject to social pressure is valuable in jobs where it is important to take actions to benefit others. In these caring-oriented jobs, which might include teaching and nursing, social pressure serves as a commitment device that ensures that the person takes costly actions on behalf of another. On the other hand, being influenced by social pressure is a disadvantage in jobs where it is 
important to be willing to take actions that may hurt others. These jobs would include supervisory jobs in which it may be important to discipline or dismiss a worker whose performance is not satisfactory.

Taking this view provides an explanation for the glass ceiling among women and for the especially poor labor-market outcomes of black men. If women are more caring then men, they will be at a disadvantage in managerial jobs. Our model also provides a novel link between fertility and women's movement into upper-level positions: if altruism is a barrier to reaching the highest levels of an organization, women who are so inclined, may make efforts to reduce their altruism. In the case of blacks, care-oriented jobs are generally well suited to less-skilled workers, but are ill suited to black men.

Social pressure is likely to be important in teams. Existing work points to difficulties providing pecuniary incentives for teams [Holmstrom 1982] and the repeated contact and similar positions of team members will likely foster social pressure. In a team each member's compensation for helping others will be the help they provide. There is an incentive to make teams homogenous to foster reciprocal altruism. We expect the increase in teamwork to be associated with an increased emphasis on people skills.

Technological change will affect the returns to people skills. On the one hand, they may lead people to work on their own. On the other hand, new technologies automate many aspects of jobs, but place more emphasis on the aspects of jobs, such as interpersonal interaction, that cannot be automated effectively. New technologies may also shift production to more complicated processes that involve more group work. If new technologies increase the importance of interpersonal interactions then (all other things equal) technological change should be favorable to women, but detrimental to blacks.

One might also expect the amount that people care about others to affect bargaining ability. An implication is that people who are particularly sensitive to others may have lower wages because they are hesitant to bargain. See Babcock and Laschever [2003] for evidence on gender differences in bargaining.

\section{Empirical Implementation}

\section{IV.A. Data Sources}

Our analysis requires measures of the importance of tasks performed in occupations and how these tasks change over time. As our main U.S. source we draw on information from the Fourth [1977] Edition and the Revised Fourth [1991] Edition of the U.S. Department of Labor's Dictionary of 
Occupational Titles (DOT). ${ }^{22}$ Examiners from the U.S. Department of Labor used a unified framework to assess 12,000 occupations along 44 objective and more subjective dimensions. ${ }^{23}$

We append DOT occupation characteristics to the Current Population Survey (CPS) March files to get a picture of the trends over a longer period, in this case 1971-2002, as shown in Figure V. Our main source of information is drawn form the Fourth [1977] Edition of the DOT because it contains more detailed information on job tasks than the Revised Fourth [1991] edition.

We also append the DOT to estimates of the demographic composition of occupations estimated from the 1980 and 1990 U.S. Censuses to investigate the effect of interpersonal skills on the employment shares of underrepresented groups. Details about the construction of the variables and the merging of databases can be found in the Data Appendix, particularly Sections A1 and A2.

To complement these analyses we draw on a number of other databases. First, for our U.S. analysis we use the National Longitudinal Survey of Youth of 1979 (NLSY79), which contains information on youth sociability. We investigate whether people who are more sociable when young are employed in occupations where interpersonal tasks are more important as adults using the DOT task measures.

We use the First [1997] and Second [2001] British Skills Survey (BSS) of the ESRC Centre on Skills, Knowledge and Organisational Performance (SKOPE) at Oxford to obtain information about job tasks in Britain. The BSS assesses the importance of 36 job activities and key skills, including interpersonal interactions, at two points in time for all jobs. ${ }^{24}$ The BSS characterizes job requirements on a five-point scale, giving a more nuanced picture than the binary information in the DOT. ${ }^{25}$

We draw information from the 1970 British Cohort Study (BCS) to address personality traits and social behavior. The BCS follows people born in the week of 5-11 April 1970. We apply information about sociability and personality at age 16 and relate this information to labor-market

\footnotetext{
${ }^{22}$ The DOT has been updated four times since its first edition in 1939 [1949, 1965, 1977, and 1991]. However, the structure has not changed significantly during these revisions. The most recent revision has let to the Occupational Information Network (O*NET) a more up-to-date source of information, but impossible to append to earlier editions.

${ }^{23}$ See the Handbook for Analyzing Jobs [U.S. Department of Labor 1972]. Other researchers have been using the DOT to analyze changing job requirements [Rumberger 1981], to address and compare different ways of skill measurement [Spenner 1990] or for the distinction between routine and non-routine job tasks in association with computerization [Autor, Levy and Murnane 2003].

${ }^{24}$ Ashton et al. [1998] provide a detailed overview of the design and present basic analyses of the BSS. Felstead, Gallie and Green [2002] provide an overview of the second BSS.

${ }^{25}$ A potential limitation of the BSS variables could be that since respondents have to rate their own occupation, the implicit scales they use could differ from person to person. There is evidence that self-assessment provides satisfactory results, however. Spenner [1990] presents evidence that there is a high correlation between self-reported job requirements and measures obtained from controlled experiments and expert evaluation, such as the DOT.
} 
outcomes at age 30 in 2000. To compare current job tasks with sociability at younger ages we append information on the tasks performed in three-digit occupations estimated in the BSS to the BCS. Table A2 in the Data Appendix shows the definitions of the sociability variables in the BCS and the NLSY.

Finally, we use German data collected by the Bundesinstitut für Berufsbildung (BIBB) in Berlin and Institut für Arbeitsmarkt- und Berufsforschung der Bundesanstalt für Arbeit (IAB) in Nürnberg. This BIBB/IAB database is representative for the German population and contains worker surveys in 1979, 1985, 1991 and 1998, with information about a worker's job tasks. For consistency we only use West-German workers. ${ }^{26}$ An advantage of the BIBB/IAB is that it contains four waves of data on job tasks over a relatively long period of time.

\section{IV.B. Interpersonal Interactions}

To identify variables that best measure interpersonal interactions, we aggregated DOT job task information to a relevant subset using the definitions of job tasks provided in the 1977 questionnaire. To estimate the importance of interpersonal tasks we selected three variables from the DOT temperaments that measure adaptability requirements of workers in specific job-worker situations. These are (i) adaptability to situations involving the interpretation of feelings, ideas or facts in terms of personal viewpoint, (ii) adaptability to influencing people in their opinions, attitudes or judgments about ideas or things, and (iii) adaptability to dealing with people beyond giving and receiving instructions. The DOT provides a binary indicator of the presence or absence of a given temperament. We also include two variables from DOT interest factors to signify interests, tastes and preferences for certain kinds of activities that are entailed in job performance. These are (i) a preference for activities involving business contact with people, and (ii) a preference for working for the presumed good of people. The interests take on 3 values, $-1,0$, or 1 . We use the sum of these variables normalized by their standard deviations. $^{27}$

For the BSS we measure the importance of interpersonal tasks by aggregating variables measuring the importance of dealing with people; working with a team of people; instructing, training or teaching people; making speeches or presentations; persuading or influencing others; selling a product; counseling, advising or caring for customers or clients; and listening carefully to colleagues. We selected three variables that are comparable to the DOT's general educational development (GED): reading,

\footnotetext{
${ }^{26}$ See Spitz [2004] for a detailed description of these data.

${ }^{27}$ Autor, Levy and Murnane [2003] apply percentile measures of the DOT scores rather than "raw" DOT scores. Results are similar when we do so.
} 
writing, and math. We also constructed job tasks on the occupational importance of planning job activities, knowledge about the organization and products, problem solving, noticing problems and (procedural) faults, and physical skills and work.

The $\mathrm{BIBB} / \mathrm{IAB}$ contains binary indicators of job tasks. We measure interpersonal interactions as the weighted sum of teaching or training; negotiating, lobbying, coordinating and organizing; serving others; helping others; selling, buying, advising customers and advertising; and entertaining or presenting. To obtain a consistent series over time, we aggregated this information at the two-digit occupational level. Table A1 in the Data Appendix offers the definitions of interpersonal interactions in our three data sources.

\section{Empirical Results}

\section{V.A. Youth Sociability and Adult Occupations}

We begin by relating people's sociability as youths to the tasks in their adult occupations. Evidence that more sociable youths go into occupations where interpersonal skills are more important will validate our measures of interpersonal tasks and show that variations in interpersonal skills affect labor market outcomes. How sociability as a youth is related to the importance of other tasks will depend on whether interpersonal skills complement other skills. If they do, people with stronger interpersonal skills will tend to be found in jobs where other tasks are more important. Sociability may also correlate with uncontrolled aspects of ability and motivation.

We present two sets of estimates, the first are from the National Longitudinal Survey of Youth of 1979 (NLSY79). The 1984 wave of the NLSY79 contains data on the number of social clubs respondents participated in during high school. The 1985 survey contains data on contemporaneous sociability (when the respondents were 20-28) and sociability at age six. Exploiting the panel aspect of the data, we regress the 1977 DOT scores for the respondents' occupations in all years on their responses to these questions. (Appendix A3 gives additional details). Our models include random effects for respondents and dummy variables for the calendar year.

The estimates are reported in Table III. The first rows show a large positive effect of all three measures of the respondents' sociability on the importance of interpersonal tasks in their adult occupations. The later rows report the effect of the sociability variables on the importance of other skills in the respondents' occupations. These models show that respondents who were more sociable when young are employed in occupations where cognitive tasks are more important. The figures in brackets 
give the portion of a standard deviation in the task variables that can be explained by a one standard deviation change in sociability. The relationship between sociability and cognitive tasks is much smaller than the relationship between sociability and interpersonal tasks, indicating that sociability is particularly important in occupations where interpersonal tasks are important.

We perform a similar analysis using the BCS and BSS. Table IV reports the regression results for the United Kingdom. The age 16 round of the BCS conducted in 1986 includes a variety of behavioral measures of sociability, including the frequency with which the respondents spent time with friends during the school year and during holidays; the frequency with which the respondents spent time with friends during their leisure time (as opposed to non-social leisure activity), and the number of friends the respondent has. The survey also asks respondents the extent to which they would describe themselves as outgoing. To obtain measures of the importance of interpersonal tasks and other tasks, we assigned to each three-digit occupation the mean of the importance of the tasks for that three-digit occupation calculated from the 2001 BSS (see Appendix A4 for details).

The first row of Table IV shows that all of the indicators of social behavior are positively related to the importance of interpersonal tasks in that three-digit occupation. The remaining rows report the relationship between the youth sociability measures and the importance of other tasks. With the exception of planning activities, which likely has an interactive component, there are no systematic relationships.

Our finding that youth sociability is strongly related to the importance of interpersonal tasks in peoples' subsequent occupations provides some validation for our measures of the importance of interpersonal tasks. It also shows that the importance of interpersonal tasks and the ability to perform those tasks are important determinants of occupation choice.

\section{V.B. Youth Sociability and Adult Wages}

Our model implies that the wage effects of interpersonal skills will vary across jobs and that jobs where interpersonal skills are important will tend to pay lower wages all other things equal. To test these hypotheses, using data from the NLSY79, we relate wages in adulthood to the importance of interpersonal interactions in occupations and an interaction between the importance of interpersonal interactions and youth sociability. Our model is,

$$
y_{i t}=\operatorname{INTERACT}_{i t}^{o} \gamma+\operatorname{SOCIABILITY}_{i}+\operatorname{INTERACT}_{i t}^{O} \beta+\operatorname{TASKS}_{i t}^{O} \theta+X_{i t} \phi+\omega_{t}+v_{i}+\eta_{i t}^{o}+\varepsilon_{i t} .
$$

Here, $y_{i t}$ denotes the individual $i$ 's $\log$ wage at time $t$; INTERACT $T_{i t}^{O}$ denotes the importance of 
interpersonal interactions in person $i$ 's occupation at time $t$ (taken from the 1977 DOT); and SOCIABILITY $Y_{i}$ denotes person $i$ 's sociability when young. The first parameter of interest is $\gamma$, which gives the direct effect of interpersonal interactions in jobs on wages. It is expected to be negative if jobs where interpersonal skills are important are more desirable. Also of interest is $\beta$, the effect of the importance of interpersonal interactions on the sociability premium. We expect $\beta>0$, so that the sociability is more beneficial in jobs where interpersonal interactions are important. In addition to these variables, the model includes measures of the importance of other tasks in the person's occupation at $t$ $\left(T A S K S_{i t}^{O}\right)$; time varying individual characteristics (a quadratic in experience and education, given by $\left.X_{i t}\right)$; and time dummy variables $\left(\omega_{t}\right)$. Individual fixed effects $\left(v_{i}\right)$ are included to account for fixed differences in wages that are correlated with our measures of interpersonal skills. Given that the data contain many observations for the same occupation, we include occupation random effects $\left(\eta_{i t}^{O}\right)$ as well as a classical error, $\varepsilon_{i t}$.

The results are shown in Table V. The first row shows that the occupations where interpersonal interactions are more important pay lower wages. A one standard deviation increase in the importance of interpersonal interactions is associated with five percent lower wages. The second row shows that youth sociability is particularly beneficial in jobs where interpersonal skills are important. With individual fixed effects, the direct effect of sociability is unidentified. In models without individual fixed effects, a one standard deviation increase in sociability at age six, for instance, raises adult wages by one percent. Given the estimates in Table V, a one standard deviation increase in the importance of interpersonal interactions comes close to doubling this effect.

Results for the United Kingdom, using 1970 BCS merged with the 2001 BSS, are reported in the bottom panel of Table V. Because we only have cross-sectional data on labor-market outcomes in the BCS, the individual fixed effects, $v_{i}$, must be dropped from the model, and the time effects, $\omega_{t}$, are incorporated in the intercept. Otherwise, the model is unmodified from above, including the use of occupation random effects. These results are generally similar. The estimate for social behavior during school term and holidays are not significant, but the other three sets of estimates reported in columns (3- 
5) suggest that a one standard deviation increase in the importance of interpersonal interactions is associated with four to nine percent lower wages. The estimates in the second row of the bottom panel show that sociability at age 16 pays in jobs demanding interpersonal skills.

\section{V.C. Technological Change and the Importance of Interpersonal Tasks}

Researchers have emphasized that computers have changed the content of many jobs [e.g., Autor, Levy and Murnane 2003, Borghans and Ter Weel 2004, and Spitz 2004] and that firms have adjusted their organizational structures to make the most of computer technology, emphasizing teams and quality circles as well as skill [Bresnahan, Brynjolfsson and Hitt 2002; Ichniowski and Shaw 2003; and Caroli and Van Reenen 2001]. These changes require workers to communicate and work others effectively. In addition, computer technology seems to substitute for routine cognitive tasks, further increasing the importance of people skills, which are hard to computerize.

We estimate the effect of technological change and innovative work practices by relating the importance of interpersonal skills in occupations to the share of the workers in that occupation that use computers and, when data permits, to the share of workers that work in teams and who are a part of quality circles. Data on computer use is available for Britain, Germany, and the United States. Data on teamwork and quality circles are only available for Britain (see Appendix A6 for details about the construction of variables).

The top panel of Table VI shows results for Britain, where the importance of interpersonal skills, computer use, and the extent of teamwork and quality circles are all estimated at the three-digit occupation level from the BSS. Columns (1)-(8) report cross-sectional estimates. These estimates (and those below) include the controls for the gender and educational composition of the industries. Columns (9)-(12) use the two cross-sections to estimate the model in differences, to further account for differences in occupations, which may be correlated with technological and organizational change and with the importance of interpersonal tasks. When the technological change and organizational change variables are included separately, all are found to have a statistically significant positive relationship with the importance of interpersonal skills. Given the positive correlation between the three variables, estimates that include all three together yield lower coefficients, but the computer use and teamwork variables remain large and statistically significant. Panel estimates are moderately lower than crosssectional estimates, but the technological and organizational change variables remain significant determinants of the importance of interpersonal tasks. 
The middle panel reports results for Germany. Here we relate the importance of interpersonal tasks to computer use in two-digit occupations (variables for organizational change are not available). Columns (1) and (5) report cross-sectional estimates for the first and last years of the BIBB/IAB, 1979 and 1998. Column (9) pools data for all four years and includes occupation and year fixed effects. We find a positive relationship between computer use and the importance of interpersonal skills. The panel estimates are noticeably smaller than the cross sectional estimates, but remain positive and significant.

The bottom panel of Table VI reports estimates for the United States. Computer use is estimated from the 1984 and 1993 Supplements to the October CPS. The importance of interpersonal styles in occupations is from the 1977 and 1991 DOT. Cross-sectional estimates of the relationship between 1984 computer use and the importance of interpersonal skills in the 1977 DOT in an occupation (reported in Column (1)) and between computer use in 1993 and 1991 DOT scores (reported in Column (5)) are large and statistically significant. Changes in DOT scores within occupations most likely understate true changes [National Academy of Sciences 1981], so it is unclear whether the weaker difference estimates reported in Column (9) indicate that the cross-sectional estimates are biased upward or if the differences model suffers from attenuation bias. Taken together, our estimates provide strong evidence that technological and organizational changes are associated with an increased emphasis on interpersonal skills.

\section{Interpersonal Skills and Underrepresented Groups}

The performance of interpersonal tasks will vary by variables such as gender, race, ethnicity, immigrant status, and English ability. This section shows that the importance of people skills affects the composition of the workforce in an occupation. We study the effect of interpersonal skills on the employment share of women in Britain, Germany, and the United States. We focus on the United States when looking at race, ethnicity, immigrant status, and language.

\section{VI.A. Gender}

Women are underrepresented in many occupations, as reviewed in Section II. Women report being more effective in interpersonal tasks than men [Borghans, Ter Weel, and Weinberg 2004b] and they report being members of more clubs in high school ${ }^{28}$, which is consistent with Gilligan's [2001] work on gender differences. Experimental studies also find that women are more likely to cooperate than

\footnotetext{
${ }^{28}$ Estimates from the NLSY79 show that after controlling for observed characteristics, women report being in .4 more clubs than men (standard error of .03).
} 
men in playing prisoner's dilemmas [Frank, Gilovich and Regan 1993 and Ortmann and Tichy 1999; Andreoni and Vesterlund 2001 find that women are more generous when it is costly]. We therefore expect women to be more likely to enter jobs where interpersonal interactions are more important.

To test this hypothesis, we regress women's relative employment, the log of women's employment relative to men's employment, in an occupation on job tasks and controls for the experience and education distribution of the occupation. Estimates based on this measure of relative employment are directly comparable to estimates of the change in labor demand.

Table VII reports results for Britain. Data on women's relative employment and the importance of tasks are constructed from the 1997 and 2001 BSS. The first sets of columns report the means and standard deviations of the task variables. Cross-section estimates for 1997 and 2001 show that occupations where interpersonal skills are more important have higher relative employment of women. Women report that interpersonal tasks are more important on their jobs than men, so exogenous changes in women's employment will bias our estimates of the effect of interpersonal skills up. To account for this effect, we instrument for the change in the importance of all of the task variables by the change in the task variables among men. In addition to the point estimates, the table reports (in brackets) the effect of the increased importance of interpersonal tasks (and the other tasks) between 1997 and 2001 on women's relative employment. To control for unobserved differences in women's employment that may correlate with the task variables, the last three columns report results for the change in women's relative employment on the change in the task variables between 1997 and 2001. While many of the task variables become insignificant in this change regression, the importance of interpersonal tasks remains positive and statistically significant. The increased importance of interpersonal tasks over the four years from 1997 to 2001 is estimated to have raised women's relative employment by 10.3 percent. The bottom panel of the table shows that the demand for women increased by between 9.2 percent and 13.1 percent depending on the elasticity of substitution, so interpersonal skills are an important factor in the increase in demand for women.

Table VIII reports analogous results for Germany. Data on women's relative employment and the importance of tasks are constructed from the 1979, 1985, 1992, and 1998 BIBB/IAB. Panel A reports the means and standard deviations of all of the tasks. Panel B reports regression estimates. In both random effects and fixed effects models, increases in the importance of interpersonal tasks are found to increase women's relative employment, with the choice of estimation method having little impact 
on the coefficient. The last set of results instrument for the change in the importance of all of the task variables by the change in the task variables among men. Given that we instrument for changes, the estimate is not statistically significant, but it is virtually identical to the changes estimated without the instrument. The increase in the importance of interpersonal job tasks over this period in Germany would have raised the demand for women by 28 percent, roughly half of the estimated increase in demand over this time period shown in the bottom panel of the table.

Table IX reports results for the United States. Data on women's relative employment are constructed from the 1980 and 1990 Census Public Use Micro Samples. Data on the importance of tasks are drawn from the 1977 and 1991 DOT. Cross-sectional estimates for women's relative employment in 1980 on the importance of tasks as measured in the 1977 DOT indicate that occupations where interpersonal skills are most important have higher relative employment of women. ${ }^{29}$ The predicted effect of a one standard deviation change in the importance of interpersonal tasks is .506 , one quarter of a standard deviation in women's relative employment across occupations. The DOT was revised in 1991, but as indicated, many of the variables used in our analysis were not updated. The last columns report regressions of changes in women's relative employment from 1980 to 1990 on changes in the DOT scores. While caution is required in interpreting these results, given the limitations of the 1991 DOT, it is noteworthy that the importance of interpersonal job tasks is found to increase women's relative employment.

To provide a sense of the magnitudes of the effects, we estimate how acceleration in the importance of interpersonal interactions after 1977 and the deceleration after 1992 accelerated and then decelerated the demand shift toward women. These estimates equal the product of the estimated effect of interpersonal interactions on women and the acceleration in 1977 and deceleration in 1992 in the importance of interpersonal interactions. Unfortunately, we only have reliable estimates of trends in the importance of interpersonal interactions arising from shifts between occupations. As indicated in Section

\footnotetext{
${ }^{29}$ Estimates in both levels and differences for that instrument for the task variables using the task variables constructed for white men here and for the other groups described below are similar, but slightly lower than those estimated without instumenting for the tasks.
} 
II, German data indicates that the total shift is likely to be between 3.6 and 20 times the betweenoccupation shift. As shown in the bottom panel of the table, when between occupation changes are assumed to account for $28(=1 / 36)$ percent of the total change, the acceleration in the importance of interpersonal interactions implies an annual acceleration of between .5 and .9 percent in the demand for women after 1977 and a roughly similar annual deceleration after 1995. These estimates are large relative to the estimated annual acceleration in demand for women after 1977 of $.9,1.8$, or 2.8 percent (based on elasticities of 1, 1.75, and 2.5, respectively) and annual deceleration after 1992 of 2.4, 3.4, or 4.3 percent.

\section{VI.B. Race and Ethnicity}

Racial and ethnic minorities may be less effective in interpersonal interactions with members of a majority culture. We test this hypothesis by estimating how the relative employment of racial and ethnic minorities in an occupation is affected by the importance of interpersonal job tasks in that occupation. As with women, our measure of relative employment is the natural logarithm of the employment of a group relative to the employment of all other groups. We use data from the United States because racial and ethnic differences are more salient in the United States and because the Census Public Use Micro Samples are considerably larger than the other data sets, which is particularly important when constructing the employment of small groups for three-digit occupations.

Columns (5)-(8) of Table IX report estimates for the relative employment of blacks. The importance of interpersonal tasks is a major determinant of the share of an occupation that is black. Estimates based on changes between 1980 and 1990 exceed estimates for the 1980 cross section, although the difference is not statistically significant. A one standard deviation increase in the importance of people skills lowers the percentage black workers by 21 percent, compared to a standard deviation in black relative employment of 79 percent.

The bottom panel of the table reports the deceleration in the demand for blacks after 1977 and the acceleration after 1992 based on the acceleration and deceleration in the increase in the importance of interpersonal interactions. Assuming that 28 percent of the increase in interpersonal interactions arises from shifts between occupations implies an annual deceleration in the demand for blacks of between .3 
and .5 percent after 1977 and a slightly smaller acceleration after 1992. Again, these are a substantial portion of the estimated annual deceleration in demand for blacks of 1, 2.2, or 3.5 percent after 1977 and acceleration of between 1 and 1.2 percent after 1992 (based on elasticities of 1, 1.75, and 2.5 respectively).

The top panel of Table $\mathrm{X}$ repeats the changes estimates for blacks and also reports analogous estimates for the other race category (American Indians, Asians, Pacific Islander's, etc.) in Columns (4)(6). Columns (7)-(9) report analogous estimates for Hispanics. Occupations that place more weight on interpersonal tasks have lower employment shares for members of other racial groups, although there is no difference for Hispanics. To quantify the effects, the figures reported in brackets give the effect of a one standard deviation increase in the importance of interpersonal tasks.

Wilson [1997] argues that employers and customers have particularly negative reactions to black men. We have tested this hypothesis by regressing the relative employment of black men on the task measures. As reported in the bottom panel of Table X, occupations where interpersonal interactions are more important have markedly lower employment of black men relative to other groups. A one standard deviation increase in the importance of interpersonal interactions lowers the relative employment of black men by 47 percent. Estimates for Hispanic men and other race men are comparable to those for black men. Thus, we find large negative effects of interpersonal interactions on the employment of men from underrepresented groups, although this effect is not limited to black men.

\section{VI.C. Immigrant Status and Language}

People with poor language skills will be at a comparative disadvantage in occupations that emphasize interpersonal interactions, especially if poor language skills are associated with less familiarity with a majority culture. The U.S. Census asks whether respondents "sometimes or always speak a language other than English at home" (Bureau of the Census [1993], B-24). The estimates presented in Column (1)-(3) of Table XI show that the importance of interpersonal tasks raises the relative employment of people who do not speak a language other than English at home even after controlling for the importance of language, which has the expected sign. A one standard deviation increase in the importance of interpersonal tasks raises the relative employment of people who do not speak a language 
other than English at home by 11.4 percent, one quarter of a standard deviation. People who report speaking a language other than English at home were asked about their ability to speak English. Column (4)-(6) reports the results of an analysis that takes as a dependent variable the natural logarithm of the employment of people who speak a language other than English at home whose English speaking ability is very good (the highest category) relative to those whose English is not as good. The estimates show that a one standard deviation increase in the importance of people skills raises the relative employment of people whose English is very good by 17.4 percent, a quarter of a standard deviation. ${ }^{30}$

Column (7)-(9) reports estimates from an analysis that takes the relative employment of foreignborn workers (those born outside of the United States or its territories) in an occupation as the dependent variable. A one standard deviation increase in the importance of people skills lowers the relative employment of immigrants by 8.4 percent, 15 percent of a standard deviation.

Taken together, our estimates show that increases in the importance of interpersonal skills in an occupation affect the employment of underrepresented groups in that occupation. As interpersonal job tasks become more important the relative employment of women and people with good English skills increases, but that of racial and ethnic minorities and immigrants declines.

\section{Conclusion}

Despite informal arguments that interpersonal interactions are important for understanding individual outcomes and are becoming more important, economists have done little to analyze their economic consequences. This paper provides a first step in this direction, developing a unified model to understand the labor-market consequences of people skills and demonstrating the relationship between people skills and labor-market outcomes.

We model interpersonal "skills" in a reduced form manner using altruism. We assume that workers are heterogeneous with respect to their altruism and that occupations require different levels of altruism - in some jobs it is important to take actions that benefit others, while in other jobs a worker must take actions that hurt others. Our model shows how worker's behavior varies optimally across jobs and how wages adjust. Our model predicts that workers who are more altruistic will be assigned to

\footnotetext{
${ }^{30}$ This result is related to the results from the Census in Lazear [1999]. He has shown that the likelihood that an immigrant speaks English is inversely elated to the proportion of the local population that speaks their native
} 
relatively caring jobs, within which they earn higher wages.

We test our model's implications using a range of data sources from the United States, Britain, and Germany and find that sociability at young ages is positively correlated with the importance of interpersonal relations in a worker's current occupation. We also find that computerization and modern forms of work organization complement the importance of interpersonal interactions. With respect to labor-market outcomes of underrepresented groups our results suggest that occupations in which interpersonal interactions are more important employ more women relative to men, but fewer racial, ethnic, and linguistic minorities and fewer immigrants.

Finally, our results shed new light on changes in the labor-market outcomes of underrepresented groups in the United States over the last four decades. We have shown that the rapid decline in the gender wage gap from the late 1970s to the early 1990s can be explained by the large increase in the importance of interpersonal tasks at work. Similarly, the slowing convergence of the gender wage gap since the mid-1990s, seems to be consistent with a slowdown in the growth rate of the importance of interpersonal interactions. Our estimates are also consistent with the opposite trends in the black-white wage gap.

\section{Data Appendix}

\section{A.1. Constructing Job Task Measures Over Time}

Our main source of information on job tasks in the United States is the Fourth [1977] version of the Dictionary of Occupational Titles (DOT). We merge information on job tasks from the DOT into the March CPS and 1980 and 1990 Censuses. Since the occupation classification in the DOT is much more detailed than the U.S. Census classification employed in the CPS, we aggregated scores in the April 1971 CPS data set to the classification used in the CPS. To do this we use the CPS April 1971 data constructed by the Committee on Occupational Classification and Analysis of the National Academy of Science [1981] - in which all occupations are classified according to the Census 1970 and the DOT classification.

The occupation classification in the CPS is changed every ten years based on new classifications used in the U.S. Census. To bridge these changes we used a common classification for the 1960s and 1970s as developed by Autor, Levy and Murnane [2003] based on information from Priebe, Heinkel and Greene [1972]. Differences between the occupational classifications used in the 1970s and the 1980s in the CPS are too large to develop a sensible crosswalk. For that reason we matched our data with the so-called Treiman file. This file contains 122,141 observations from the 1980 Census that are dual coded with both the occupational classification for the CPS in the 1970s and the 1980s and aggregated the occupational scores separately for the 1980 classification. Based on a joint classification for the CPS in the 1980s and the 1990s developed by Autor, Katz and Krueger [1998] we put the CPS classification for both decades into one framework. Subsequently, we append the DOT information to

language. In addition, he argues that these people suffer welfare losses. 
the CPS.

To investigate changes in the scores for the occupations between the Fourth version from 1977 and the 1991 Fourth Revised Edition, we matched occupation characteristics from the Revised Edition from the data set of the U.S. Department of Labor, U.S. Employment Service, and the North Carolina Occupational Analysis Field Center [1994], using the conversion tables of code and title changes from the Fourth to Revised Fourth Edition Dictionary of Occupational Titles. Table A1 lists the specific variables used to measure the importance of interpersonal tasks in the DOT and in the other datasets described below.

\section{A.2. Current Population Surveys}

We use all observations for workers, aged 18-64, to measure the importance of interpersonal interactions in the labor force, and took a sub-sample of full-time, full-year workers to calculate wages by gender, skill and occupation similar to the procedure followed by Katz and Murphy [1992]. To measure supply we weighted all observations by hours worked times weeks worked. For the years in the CPS for which the number of weeks worked are not known, we assumed that part year workers worked 50 percent of the year. People who worked full-time were assumed to work 40 hours per week. Wage results are based on full-time, full-year workers only. Top-coded wages have been multiplied by 1.4. We estimated wage equations for each year in the sample separately, including dummy variables for sex, race (black, other), a quartic in potential experience, dummy variables for individual levels schooling, and state dummy variables. The relative wage series for women and blacks reported are the estimated parameters for these groups in each year.

\section{A.3. NLSY and Census}

We use data from the National Longitudinal Survey of Youth of 1979 (NLSY79) to estimate the effect of people skills on marriage, fertility, and labor-market outcomes. The 1984 wave of the NLSY79 contains data on the number of social clubs respondents participated in during high school. The 1985 survey contains data on sociability at age 6 and as an adult, when the respondents were 20-28 years old. Table A2 lists the specific variables we used to measure sociability in the NLSY79 and in the other datasets discussed below. We estimate the relationship between these sociability variables and the tasks in adult occupations by assigning respondents the 1977 DOT scores associated with the three-digit occupation they hold. We also estimate the relationship between sociability and wages using the hourly rates of pay, which were converted to 1982-1990 dollars. Respondents with hourly rates of pay beneath $\$ 1$ per hour or above $\$ 100$ per hour were deleted from the sample. We exploit the panel aspects of the NLYS79 by using data for all years for which wages are reported. The NLSY79 is attractive because it contains a wealth of information about individuals, including parents' education, the respondents' score on the Armed Forces Qualifying Test, and characteristics of the household in which the respondent was raised.

We use the five percent Public Use Micro Samples of the 1980 and 1990 Census to estimate the share of workers in each three-digit occupation who are black; other race (American Indians, Asians, Pacific Islander's, etc.); from a Hispanic background; who speak a language other than English at home; whose English is very good (the highest category) conditional on speaking a language other than English at home; and who were born outside of the United States and its territories. The sample was restricted to people who held a job at the time of the survey between 18 and 65, who were not enrolled in school. All observations with imputed values for any variable used in the analysis were deleted. Individuals were weighted using the person weight. These measures of the demographic composition of each occupation were then merged to measures of task importance from the 1977 DOT.

\section{A.4. BSS and BCS}

The First [1997] and Second [2001] British Skills Surveys (BSS) are two cross-sections of a 
representative sample of the British population. The ESRC Centre on Skills, Knowledge and Organisational Performance (SKOPE) initiated the first edition of the BSS in 1997 aimed at "investigating the skills used at work in Britain ... [and] to collect data from individual job-holders on a rich array of variables characterizing British jobs. The intention is that the survey generates a more valid and detailed picture of skills than is normally available from examining individuals' qualifications or their occupations" [Ashton et al. 1998, 5]. The most innovative feature of the data is that it is derived from a combination of job analysis principles and procedures with the conventional techniques of a representative survey. The second BSS is an update of the first and its structure was little altered. A sample of 2,467 job holders were interviewed face-to-face for the 1997 survey. The 2001 survey includes 4,470 workers. The interviewers assess the importance of 36 job activities and key skills, including problem solving, noticing mistakes, mathematical ability, reading and writing, physical skills, the ability to plan activities, knowledge about products and the workplace and interpersonal interactions. We construct nine job task categories out of these detailed job tasks (see e.g., Table A1 in Section A.7).

The 1970 Birth Cohort Study (BCS) is similar to the earlier National Child Development Study (NCDS) and began as the British Birth Survey, which includes over 17,000 babies born in Britain in the week 5-11 April 1970. ${ }^{31}$ Four major follow up surveys in 1975, 1980, 1986, and 1996 monitor the health, education, social and economic circumstances of the surviving cohort members. We focus on the sociability questions asked in 1986 when the cohort members were 16 years old. The latest major survey was held in 2000 and reviews the members' labor-market status at the age of 30 . We selected those cohort members that were in paid work and not self employed in 2000.The average (standard deviation) gross hourly wage is GB£ 7.43 (9.25) in 1997 and increases to GB£ 9.75 (10.95) in 2001.

For some of the empirical analysis we have aggregated the individual data into three-digit 1990 U.K. Standard Occupational Classification (SOC90) codes, of which there are $371 .{ }^{32}$ We use all observations for non-self employed workers. For the BSS we selected workers aged 20-60.

In the analysis carried out in Section V.A we appended the 2001 BSS to the 2000 BCS, acknowledging the one-year difference between the two surveys. To do so, we assigned the mean importance of the nine job tasks by occupation from the BSS to each individual cohort member in the BCS working in that occupation. We then estimated the effects of sociability at age 16 on the importance of job tasks. We also estimated the returns to sociability by using log hourly wages from the 2000 BCS. Using log hourly wages from the BSS, adjusted for age, yields qualitatively similar results. Table A2 presents the definitions and some descriptive statistics of our constructs of sociability.

\section{A.5. BIBB/IAB}

The data collected by the Bundesinstitut für Berufsbildung (BIBB) in Berlin and Institut für Arbeitsmarkt- und Berufsforschung der Bundesanstalt für Arbeit (IAB) in Nürnberg are representative surveys of the German workforce. This BIBB/IAB database contains four cross-sectional worker surveys conducted in 1979, 1985, 1991 and 1998. The surveys contain standard demographic and labor-market variables and rich information about workers' jobs, job attributes, the tools used in these jobs, the skills necessary to perform a job, and how these skills were obtained. The sampling frame for the survey is the employed German population age 16 to 65 . Each survey has about 30,000

\footnotetext{
${ }^{31}$ We use the BCS instead of the earlier NCDS because the NCDS does not contain measures of sociability.

${ }^{32}$ For Britain samples of the Standard Occupational Classification 1990 (SOC90) are available. The SOC90 was published to replace both the Classification of Occupations 1980 (CO80) and the Classification of Occupations and Dictionary of Occupational Titles (CODOT). The SOC90 includes nine major groups divided into 22 sub-major groups of occupations. These 22 groups can be divided into 371 unit groups, which we define as occupations. These unit groups are the aggregate results of over 26,000 job titles.
} 
respondents. We use the largest sample possible, only removing workers from former East Germany included in the survey since 1991, and the self-employed and unemployed. The questions in the three surveys are similar but not exactly comparable.

To compare occupations across the surveys, we aggregated the data into consistent occupations at the two-digit level. Because of changes in the German occupational classification it is impossible to match the data at a more disaggregated level. All four waves are categorized according to the 1988 German occupational classification, which yields 83 occupations in all four years.

\section{A.6. Computerization, Organizational Change and Teamwork}

Data on computer use at work in the United States is in the School Enrollment Supplements to the 1984, 1989, 1993, and 1997 October CPS. Individual computer use is calculated as the fraction of currently employed workers who answered yes to the question, "Do you use a computer directly at work?" The survey defines a computer as a desktop terminal or PC with keyboard and monitor and does not include an electronic cash register or a hand-held data-device. 60,396, 58,401, 59,710, and 52,753 observations were used to calculate these frequencies in 1984, 1989, 1993, and 1997, respectively. Since our DOT variables reflect the period 1977-1991, we only use the 1984 and 1993 surveys. When we substitute the 1984-1997 change in computer use the results are qualitatively similar but of a slightly higher magnitude. From this constructed variable computer use in the United States increases from 26.1 percent in 1984 to 54.0 percent in 1997.

For Germany the questions on computer use differ slightly between 1979 and the later waves. For the 1979 survey we combine answers to two questions. The first asked about the use of "computers, terminals, or monitors," the second inquired about word processors. In the later surveys there are six categories - computers on shop floors, office computers, PCs, terminals, word processors, and CAD systems - which we combine into one dummy variable. Using this procedure, computer use in Germany increases from 5.6 percent in 1979 to 53.7 percent in1998.

To compute computer use in Britain we use responses to "How important is using a computer or computerized equipment in your job?" in the two waves of the BSS. If the answer is essential, very important, or slightly important computer use is equal to one. If the answer is does not apply, computer use is equal to zero. This yields computer use in Britain equal to 69.2 percent in 1997 and 78.1 percent in 2001. When we use the more gradual scale instead of a dummy variable, the regression results remain similar in qualitative terms, although the significance drops somewhat. The information about the organization of work in teams is taken from the question "How important is working in a team of workers?" We use the five possible answer categories as the independent variable in the regression analysis. Finally, organizational change is measured by the extent to which new organizational practices, such as quality circles, have been introduced in recent years.

\section{References}

Akerlof, George A., and Rachel E. Kranton, "Identity and Economics of Organizations," Working Paper, Berkeley, 2003.

Altonji, Joseph G. and Rebeccca M. Blank, "Race and Gender in the Labor Market," in Handbook of Labor Economics, Vol. 3C, Orley Ashenfelter and David Card, eds. (New York and Oxford: Elsevier Science, North Holland), 3143-3259.

Andreoni, James and Lise Vesterlund, "Whis is the Fairer Sex? Gender Differences in Altruism," Quarterly Journal of Economics, CXVI (2001), 293-312.

Arrow, Kenneth I., “Gifts and Exchanges," Philosophy and Public Affairs, I (1972), 343-362.

Ashton, David, Bryn Davies, Alan Felstead and Francis Green, "Work Skills in Britain," SKOPE 
Monograph No. 1, University of Oxford, 1998.

Autor, David H., Lawrence F. Katz and Alan B. Krueger, "Computing Inequality: Have Computers Changed the Labor Market?” Quarterly Journal of Economics, CXII (1998), 1169-1214.

Autor, David H., Frank Levy, and Richard J. Murnane, "The Skill Content of Recent Technological Change: An Empirical Exploration,” Quarterly Journal of Economics, CXVIII (2003), 12791333.

Babcock, Linda, and Sara Laschever, Women Don't Ask: Negotiations and the Gender Divide (Princeton NJ: Princeton University Press, 2003).

Bai, Jushan, "Estimation of a Change Point in Multiple Regression Models," Review of Economics and Statistics, LIX (1997), 551-563.

Bai, Jushan, Robin L. Lumsdaine, and James H. Stock, "Testing for and Dating Common Breaks in Multivariate Time Series," Review of Economics Studies, LXIV (1998), 395-432

Bailey, Martha J., "More Power to the Pill: The Effect of Contraceptive Freedom on Women's Labor Supply," Working Paper, Vanderbilt University, May 2004.

Bayard, Kimberly, Judith Hellerstein, David Neumark, and Kenneth R. Troske, "New Evidence on Sex Segregation and Sex Differences in Wages from Matched Employer-Employee Data," Journal of Labor Economics, XXI (2003), 887-922.

Becker, Gary S., and Kevin M. Murphy, Social Economics: Market Behavior in a Social Environment (Cambridge MA: Harvard University Press, 2000).

Bertrand, Marianne, and Kevin F. Hallock, “The Gender Gap in Top Corporate Jobs," Industrial and Labor Relations Review, LV (2001), 3-21.

Black, Sandra E., and Elizabeth Brainerd, "Importing Equality? The Impact of Globalization on Gender Discrimination,” Industrial and Labor Relations Review, LVII (2004), 540-559.

Black, Sandra E., and Chinui Juhn, "The Rise of Female Professionals: Are Women Responding to Skill Demand?" American Economic Review, XC (2000), 450-455.

Blau, Francine D., and Andrea H. Ferber, The Economics of Women, Men, and Work (Englewood Cliffs NJ: Prentice Hall, 1992).

Blau, Francine D., and Lawrence M. Kahn, "Swimming Upstream: Trends in the Gender Wage Differential in the 1980s," Journal of Labor Economics, XV (1997), 1-42.

Blau, Francine D., and Lawrence M. Kahn, "The U.S. Gender Pay Gap in the 1990s: Slowing Convergence,” National Bureau of Economic Research Working Paper No. 10853, 2004.

Borghans, Lex, and Bas ter Weel, "What Happens When Agent $T$ Gets a Computer? The Labor Market Impact of Cost Efficient Computer Adoption," Journal of Economic Behavior and Organization, LIV (2004), 137-151.

Borghans, Lex, Bas ter Weel, and Bruce A. Weinberg, "People People,” Working Paper, Maastricht University and Ohio State University, March 2004a.

Borghans, Lex, Bas ter Weel, and Bruce A. Weinberg, "The Labor-Market Effectiveness of Interpersonal Interactions: Evidence from Britain and Germany," Working Paper, Maastricht University and Ohio State University, October 2004b. 
Borjas, George, "The Earnings of Male Hispanic Immigrants in the United States," Industrial and Labor Relations Review, XXXV (1982), 343-353.

Borjas, George, "Assimilaton and Changes in Cohort Quality Revisited: What Happened to Immigrant Earnings in the 1980s?” Journal of Labor Economics, XIII (1995), 201-245.

Bound, John, and Richard B. Freeman, "What Went Wrong? The Erosion of Relative Earnings and Employment Among Young Black Men in the 1980s," Quarterly Journal of Economics, CVII (1992), 201-232.

Bresnahan, Timothy F., Erik Brynjolfsson, and Lorin M. Hitt, "Information Technology, Workplace Organization, and the Demand for Skilled Labor: Firm-Level Evidence," Quarterly Journal of Economics, CXVII (2002), 339-376.

Brown, Charles, "Black-White Earnings Ratios Since the Civil Rights Act of 1964: The Importance of Labor Market Dropouts," Quarterly Journal of Economics, IXC (1984), 31-44.

Brown, Charles, and Mary Corcoran, "Sex-Based Differences in School Content and the Male/Female Wage Gap," Journal of Labor Economics, XV (1997), 431-465.

Card, David, and Alan B. Krueger, "School Quality and Black-White Relative Earnings: A Direct Assessment," Quarterly Journal of Economics, CVII (1992), 151-200.

Card, David, and Alan B. Krueger, "Trends in Relative Black-White Earnings Revisited," American Economic Review, LXXXIII (1993), 85-91.

Card, David and Thomas Lemieux, "Changing Wage Structure and Black-White Differentials Among Men and Women: A Longitudinal Analysis," American Economic Review, LXXXIV (1994), 2933 .

Carnegie, Dale, How to Win Friends and Influence People (New York NY: Simon and Schuster, 1936).

Caroli, Eve, and John Van Reenen, "Skill-Biased Organizational Change? Evidence from a Panel of British and French Establishments," Quarterly Journal of Economics, CXVI (2001), 14491492.

Chandra, Amitabh, "Labor Market Dropouts and the Racial Wage Gap," American Economic Review, XC (2000), 333-338.

Chandra, Amitabh, "Is the Convergence in the Racial Wage Gap Illusory?" National Bureau of Economic Research Working Paper No. 9476, 2003.

Cherniss, Cary, and Daniel Goleman, The Emotionally Intelligent Workplace (San Francisco CA: Jossey-Bass, 2001).

Coleman, James S., Foundations of Social Theory (Cambridge MA: Harvard University Press, 1990).

Collins, William J., "The Labor Market Impact of State-Level Anti-Discrimination Laws, 1940-1960," National Bureau of Economic Research Working Paper No. 8310, 2001.

Committee on Occupational Classification and Analysis of the National Academy of Science, Dictionary of Occupational Titles (DOT): Part I - Current Population Survey, April 1971, Augmented with DOT Characteristics and Part II - Fourth Edition Dictionary of DOT Scores for 1970 Census Categories (1981), distributed by the ICPSR. 
Costa, Dora L., and Matthew E. Kahn, "Cowards and Heroes: Group Loyalty in the American Civil War," Quarterly Journal of Economics, CXVIII (2003), 519-548.

Cutler, David M., and Edward L. Glaeser, “Are Ghettos Good or Bad?” Quarterly Journal of Economics, CXII (1997), 827-872.

Cutler, David M., Edward L. Glaeser, and Jacob L. Vigdor, "The Rise and Decline of the American Ghetto," Journal of Political Economy, CVII (1999), 455-506.

DiPasquale, Denise, and Edward L. Glaeser, "Incentives and Social Capital: Are Homeowners Better Citizens?’ Journal of Urban Economics, XLV (1999), 354-384.

Donohue, John J., and James J. Heckman, "Continuous versus Episodic Change: The Impact of Affirmative Action and Civil Rights Policy on the Economic Status of Blacks," Journal of Economic Literature, XXIX (1991), 1603-1644.

Donohue, John J., James J. Heckman, and Petra E. Todd, "The Schooling of Southern Blacks: The Roles of Legal Activism and Private Philanthropy, 1910-1960," Quarterly Journal of Economics, CXVII (2002), 225-268.

Felstead, Alan, Francis Green, and Duncan Gallie, “Work Skills in Britain 1986-2001,” Nottingham, DfES Publications, May 2002.

Ferreira, Daniel, “Group Loyalty and Incentive Pay,” Working Paper, University of Chicago, 2002.

Fortin, Nicole. M., "Greed, Altruism, and the Gender Wage Gap," Working Paper, University of British Columbia, 2004.

Freeman, Richard B., "Changes in the Labor Market for Black Americans," Brookings Papers on Economic Activity, II (1973), 67-120.

Gardner, Howard, Frames of Mind: The Theory of Multiple Intelligences (New York, NY: Basic Books, 1983).

Gilligan, Carol, In A Different Voice: Psychological Theory and Women's Development (Cambridge, MA: Harvard University Press, 2001).

Glaeser, Edward L., David Laibson, and Bruce Sacerdote, "An Economic Approach to Social Capital," Economic Journal, CXII (2002), F437-F458.

Glaeser, Edward L., David Laibson, José A. Scheinkman, and Christine L. Soutter, "Measuring Trust," Quarterly Journal of Economics, CXV (2000), 811-846.

Glaeser, Edward L., Bruce Sacerdote, and José A. Scheinkman, "Crime and Social Interactions," Quarterly Journal of Economics, CXI (1996), 507-548.

Goldin, Claudia, Understanding the Gender Gap (New York, NY: Oxford University Press, 1990).

Goldin, Claudia, “The Rising (and then Declining) Significance of Gender," National Bureau of Economic Research Working Paper No. 8915, 2002.

Goldin, Claudia, "The Long Road to the Fast Track: Career and Family," National Bureau of Economic Research Working Paper No. 10331, 2004a.

Goldin, Claudia, "From the Valley to the Summit: The Quiet Revolution that Transformed Women's Work," National Bureau of Economic Research Working Paper No. 10335, 2004 b.

Goldin, Claudia, and Lawrence F. Katz, “The Power of the Pill: Oral Contraceptives and Women's 
Career and Marriage Decisions," Journal of Political Economy, CX (2002), 730-770.

Goleman, Daniel, Emotional Intelligence: Why It Can Matter More Than IQ (London: Bloomsbury, 1996).

Greenwood, Jeremy, and Nezih Guner, "Marriage and Divorce since World War II: Analyzing the Role of Technological Progress on the Formation of Households," National Bureau of Economic Research Working Paper No. 10772, 2004.

Hamermesh, Daniel S., and Jeff E. Biddle, "Beauty and the Labor Market," American Economic Review, LXXXIV (1994), 1174-1194.

Heckman, James J., "Effects of Child-Care Programs on Women's Work Effort,” Journal of Political Economy, LXXXII (1974), S136-S163.

Heckman, James J., Thomas M. Lyons, and Petra E. Todd, “Understanding Black-White Wage Differentials, 1960-1990," American Economic Review, XC (2000), 344-349.

Hoff, Karla and Arijt Sen (2003). "A Simple Theory of the Extended Family System and Market Barriers to the Poor," in Poverty Traps, Samuel Bowles, Steven N. Durlauf and Karla Hoff, eds. (New York and Santa Fe: Russell Sage Foundation and Santa Fe Institute).

Holmstrom, Bengt R., "Moral Hazard in Teams," Bell Journal of Economics, XIII (1982), 324-340.

Ichniowski, Casey, and Kathryn Shaw, "Beyond Incentive Pay: Insiders' Estimates of the Value of Complementary Human Resource Management Practices," Journal of Economic Perspectives, XVII (2003), 155-180.

Jaynes, Gerald D., “The Labor Market Status of Black Americans: 1939-1985," Journal of Economic Perspectives, IV (1990), 9-24.

Juhn, Chinhui, "Decline in Male Labor Market Participation: The Role of Declining Market Opportunities,” Quarterly Journal of Economics, CVII (1992), 79-121.

Juhn, Chinhui, and Dae Il Kim, “The Effects of Rising Female Labor Supply on Male Wages," Journal of Labor Economics, XVII (1999), 23-48.

Juhn, Chinhui, and Kevin M. Murphy, "Wage Inequality and Family Labor Supply," Journal of Labor Economics, XV (1997), 72-97.

Juhn, Chinhui, Kevin M. Murphy, and Brooks Pierce, “Accounting for the Slowdown in Black-White Wage Convergence," in Workers and Their Wages: Changing Patterns in the United States, M. Kosters, ed. (Washington DC: American Enterprise Institute Press), 107-143.

Kandel, Eugene, and Edward P. Lazear, "Peer Pressure and Partnerships," Journal of Political Economy, C (1992), 801-817.

Katz, Lawrence F., and Kevin M. Murphy, "Changes in Relative Wages, 1963-1987: Supply and Demand Factors," Quarterly Journal of Economics, CVII (1992), 35-78.

Knack, Stephen, and Philip Keefer, "Does Social Capital Have an Economic Pay-Off? A CrossCountry Investigation,” Quarterly Journal of Economics, CXII (1997), 1251-1288.

Kuhn, Peter, and Catherine Weinberger, "Leadership Skills and Wages,” Working Paper No. 482, Institute for the Study of Labor (IZA), Bonn, 2002.

Lazear, Edward P., “Culture and Language,” Journal of Political Economy, CVII (1999), S95-S126. 
Levin, Doron P., "What BMW Sees in South Carolina," New York Times, Section 3, p. 5 (April 11, 1999).

Machin, Stephen, Steven McIntosh, Anna Vignoles, and Tarja Viitanen, "Basic Skills, Soft Skills and Labour Market Outcomes: Secondary Analysis of the National Child Development Study," Research Report No. 250, DfEE Research Centre, London, 2001.

Marvel, Mary K., and Howard P. Marvel, "The Ratio of Beef Cubes to Onion (6:1) in Hungarian Goulash and Public Sector Contracting: Market-Like or Market-Lite?' Policy Currents, XII (2003), 2-4

Meyer, Bruce D., and James Sullivan, "The Effects of Welfare and Tax Reform: The Material WellBeing of Single Mothers in the 1980s and 1990s," Journal of Public Economics, LXXXVIII (2004), 1387-1420.

Mincer, Jacob, and Solomon Polachek, "Family Investment in Human Capital: Earnings of Women," Journal of Political Economy, LXXXII (1974), S76-S108.

Möbius, Markus M., and Tanya S. Rosenblat, "Why Beauty Matters," Working Paper, Harvard University, 2004.

Montgomery, Edward, and William Wascher, "Cross-Industry Differences in Race and Gender Wage Differentials," Industrial Relations, XXVI (1987), 284-290.

Mulligan, Casey B., and Yona Rubinstein, "The Closing Gender Gap as a Roy Model Illusion,” National Bureau of Economic Research Working Paper No. 10892, 2004.

National Academy of Sciences, Committee on Occupational Classification and Analysis, "Fourth Edition Dictionary of DOT Scores for 1970 Census Categories,” ICPSR Document No. 7845, Ann Arbor, MI, 1981.

Neal, Derek, “The Measured Black-White Wage Gap Among Women Is Too Small,” Journal of Political Economy, CXII (2004), S1-S28.

Neal, Derek, and William R. Johnson, "The Role of Premarket Factors in Black-White Wage Differences," Journal of Political Economy, CIV (1996), 869-895.

Persico, Nicola, Andrew Postlewaite, and Dan Silverman, 'The Effect of Adolescent Experience on Labor Market Outcomes: The Case of Height," Journal of Political Economy, CXII (2004), 1019-1053.

Priebe, John A., Joan Heinkel, and Stanley Greene, "1970 Occupation and Industry Classifications in Terms of their 1960 Occupation an Industry Elements,” Census Bureau Technical Paper No. 26, 1972.

Putnam, Robert D., Making Democracy Work: Civic Traditions in Modern Italy (Princeton NJ: Princeton University Press, 1993).

Rotemberg, Julio J., "Human Relations in the Workplace,” Journal of Political Economy, CII (1994), 684-717.

Rumberger, Russell W., "The Changing Skill Requirements of Jobs in the U.S. Economy," Industrial and Labor Relations Review, XXXIV (1981), 578-590.

Smith, James P., "Affirmative Action and the Racial Wage Gap," American Economic Review, LXXXIII (1993), 79-84. 
Smith, James P., and Finis R. Welch, "Black-White Earnings and Employment: 1960-1970,” American Economic Review, LIVII (1977), 323-338.

Smith, James P., and Finis R. Welch, "Affirmative Action and Labor Markets," Journal of Labor Economics, II (1984), 269-301.

Smith, James P., and Finis R. Welch, "Black Economic Progress After Myrdal," Journal of Economic Literature, XXVI (1989), 519-564.

Spenner, Kenneth I., "Skill: Meaning, Methods and Measures," Work and Occupations, XVII (1990), 399-421.

Spitz, Alexandra, "Are Skill Requirements in the Workplace Rising? Stylized Facts and Evidence on Skill-Biased Technological Change," ZEW Working Paper, Mannheim, 2004.

Sternberg, Robert J, “Toward a Triarchic Theory of Human Intelligence," The Behavioral and Brain Sciences, VII (1984), 269-315.

U.S. Department of Labor, Manpower Administration, Handbook for Analyzing Jobs (Washington, DC, 1972).

U.S. Department of Labor, Employment and Training Administration, Dictionary of Occupational Titles: Fourth Edition (Washington, DC, 1977).

U.S. Department of Labor, Employment and Training Administration, Dictionary of Occupational Titles: Revised Fourth Edition (Washington, DC, 1991).

U.S. Department of Labor, U.S. Employment Service, and the North Carolina Occupational Analysis Field Center, Dictionary of Occupational Titles: Revised Fourth Edition, 1991 (1994), distributed by the ICPSR.

Weinberg, Bruce A., "Computer Use and the Demand for Female Workers," Industrial and Labor Relations Review, LIII (2000), 290-308.

Welch, Finis R., "Growth in Women's Relative Wages and in Inequality Among Men: One Phenomenon or Two?" American Economic Review, XC (2000), 444-449.

Wilson, William J., When Work Disappears: The World of the New Urban Poor (New York, NY: Alfred Knopf, 1997).

Xenogiani, Theodora, "Demand for Women and Workplace Organization Changes. The Role of the Demand for Skills,” Working Paper LSE, 2002. 
Figure I. Earnings of Women and Blacks, 1963-2002

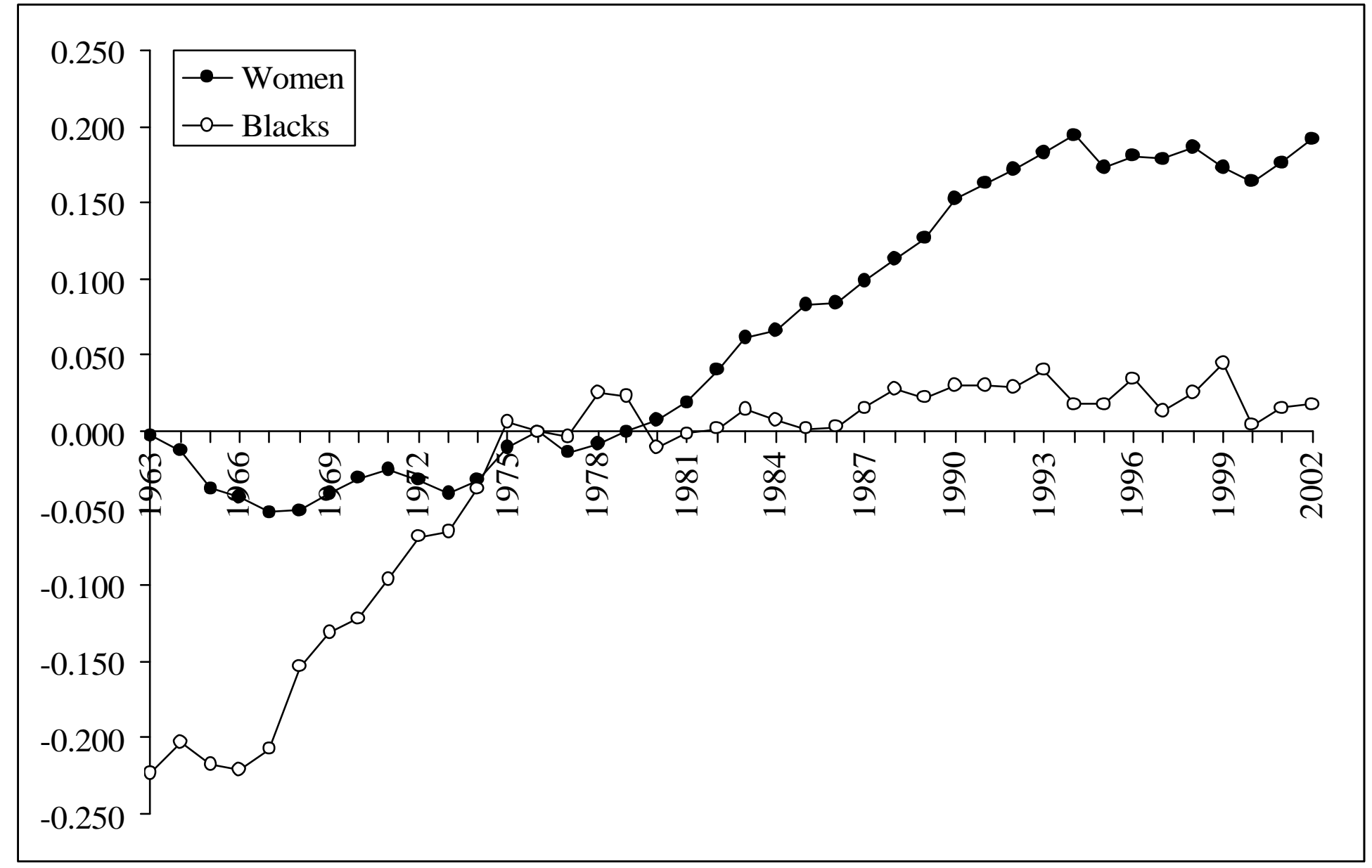

Note: Monthly earnings of women and blacks, working full-time, full year, from the CPS March supplements, regression adjusted for educational levels, experience (fourth order polynomial) and states $(1976=0)$. 
Figure II. Employment of Women and Blacks, 1963-2002

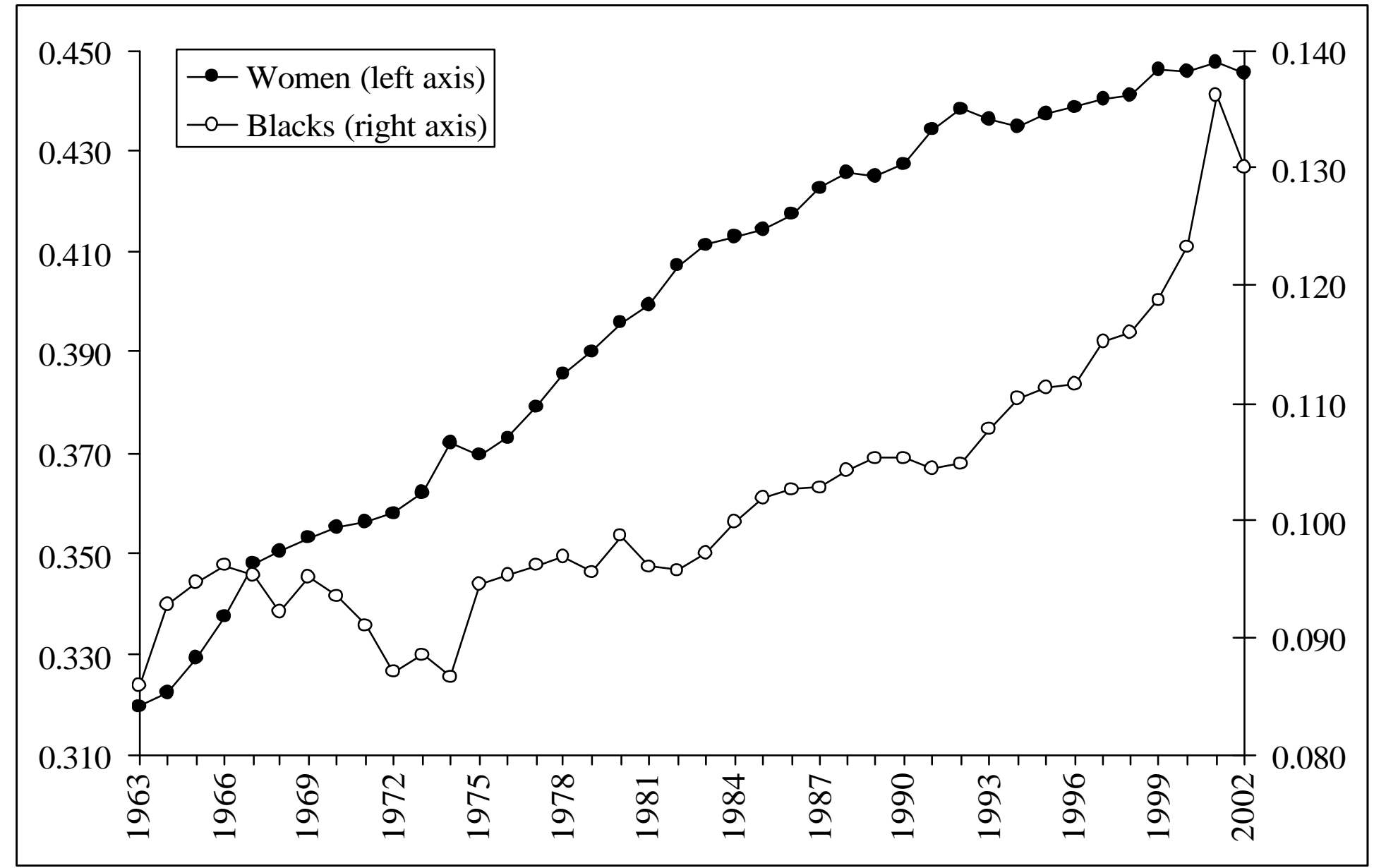

Note: Employment of women and blacks, weighted by their hours of work and weeks worked, from the CPS March supplements. 
Figure III. CES Demand Indices for Women, 1963-2002

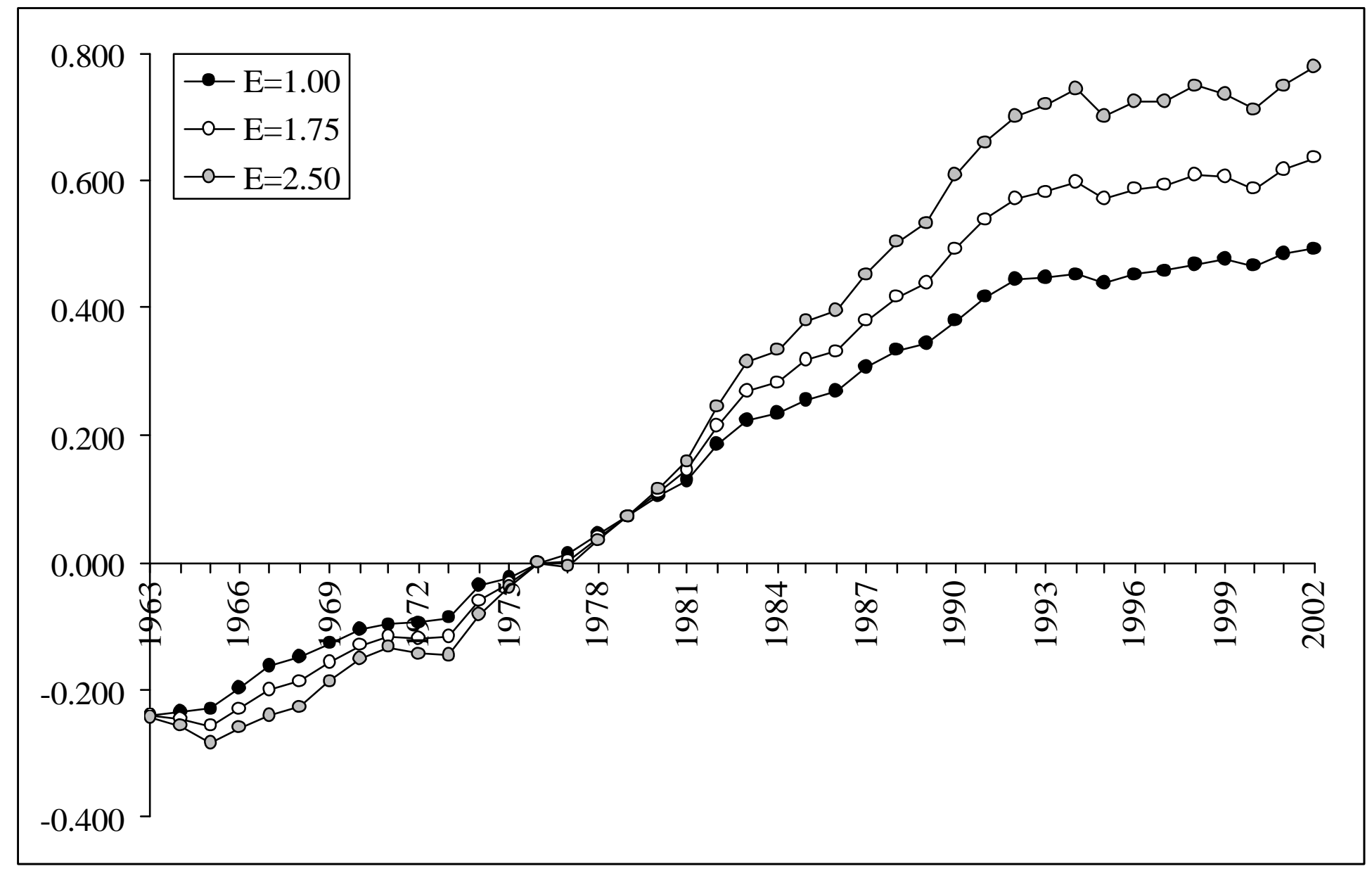

Note: Demand for women, based on demand $=\ln ($ fraction women/(1- fraction women $))+\mathrm{s} \ln ($ wage $)$, weighted by their hours of work and weeks worked, from the CPS March supplements (1976=0), for $\mathrm{s}=1, \mathrm{~s}=2.5$, and $\mathrm{s}=4$. 
Figure IV. CES Demand Indices for Blacks, 1963-2002

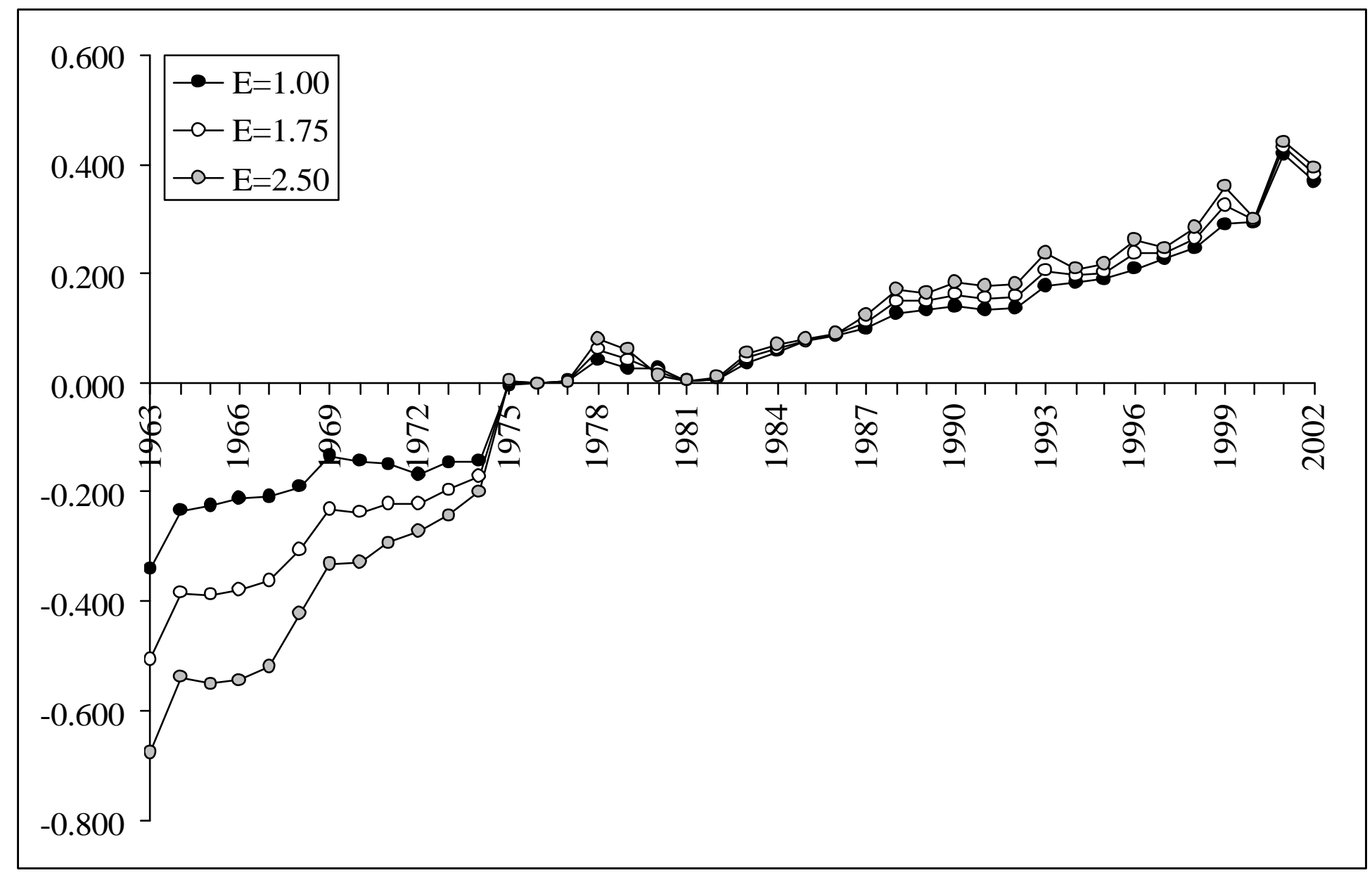

Note: Demand for blacks, based on demand $=\ln ($ fraction blacks/ $(1$ - fraction blacks $))+s \ln ($ wage $)$, weighted by their hours of work and weeks worked, from the CPS March supplements $(1976=0)$, for $\mathrm{s}=1, \mathrm{~s}=2.5$, and $\mathrm{s}=4$. 
Figure V. Importance of Interpersonal Tasks, 1970-2002

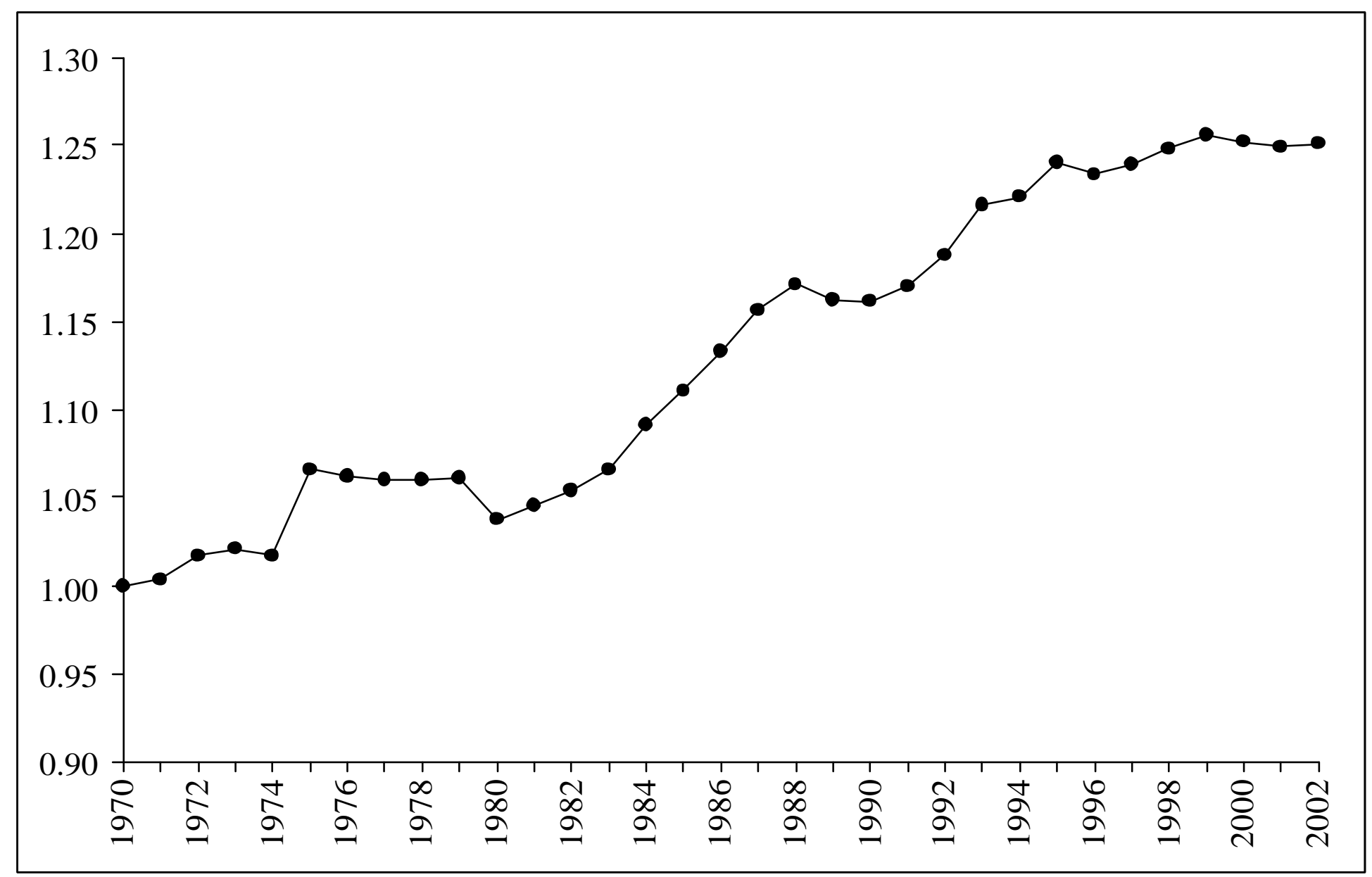

Note: Figure V is constructed using 1977 DOT task measures by occupation paired to employment data from the CPS 1971-2003. All series are weighted by the size of the occupation. See the Data Appendix for the definition of the DOT task measures $(1970=1)$. 
Table I

Analysis of Breaks in Imputed Demand for Women and Blacks and in the Importance of Interpersonal Tasks

\begin{tabular}{|c|c|c|c|c|c|c|c|c|c|c|}
\hline \multicolumn{7}{|c|}{ Panel A: Estimation of the Break Years } & \multicolumn{4}{|c|}{$\begin{array}{l}\text { Panel B: Size of the Breaks Taking } 1977 \text { and } 1992 \\
\text { as Break Years }\end{array}$} \\
\hline Elasticity & $1^{\text {st }}$ Break & Confidence Interval & $2^{\text {nd }}$ Break & Confidence Interval & $\chi 2$-Test & P-Value & $\begin{array}{c}1977 \\
\text { Change }\end{array}$ & St. Error & $\begin{array}{c}1992 \\
\text { Change }\end{array}$ & St. Error \\
\hline \multicolumn{11}{|c|}{ Women } \\
\hline 1 & 1975 & $(1973,1978)$ & 1992 & $(1991,1993)$ & 227.26 & 0.00 & 0.009 & $(0.001)$ & -0.024 & $(0.001)$ \\
\hline 1.75 & 1976 & $(1975,1977)$ & 1992 & $(1991,1993)$ & 219.60 & 0.00 & 0.018 & $(0.001)$ & -0.034 & $(0.002)$ \\
\hline 2.5 & 1977 & $(1976,1978)$ & 1992 & $(1991,1993)$ & 177.49 & 0.00 & 0.028 & $(0.002)$ & -0.043 & $(0.002)$ \\
\hline \multicolumn{11}{|c|}{ Blacks } \\
\hline 1 & 1978 & $(1972,1989)$ & 1997 & $(1993,-)$ & 12.27 & 0.00 & -0.010 & $(0.003)$ & 0.012 & $(0.003)$ \\
\hline 1.75 & 1977 & $(1973,1981)$ & 1997 & $(1983,-)$ & 43.03 & 0.00 & -0.023 & $(0.003)$ & 0.011 & $(0.004)$ \\
\hline 2.5 & 1978 & $(1969,1979)$ & 1983 & $(1967,1996)$ & 88.23 & 0.00 & -0.035 & $(0.003)$ & 0.010 & $(0.004)$ \\
\hline \multicolumn{11}{|c|}{ Interpersonal Interactions } \\
\hline & 1981 & $(1977,1986)$ & 1994 & $(1987,-)$ & 14.94 & 0.00 & 0.011 & $(0.002)$ & -0.009 & $(0.003)$ \\
\hline
\end{tabular}

Note: Panel A reports years of breaks with five percent lower and upper bounds and tests for statistical significance of breaks when break years are estimated Panel B provides estimates of the break coefficients when 1977 and 1992 are taken as break years, which are the years that are estimated to be the break years when breaks are estimated simultaneously for the three series. 
Table II

Comparative Statics

\begin{tabular}{llll}
\hline Effect on: & Changing $\alpha$ by Changing $x_{W}$ & Changing $\alpha$ by Changing $x_{F}$ & Changing $\theta$ \\
\hline Action & $-\frac{w \theta}{S O C} \frac{\partial \alpha}{\partial x_{W}}$ & $-\frac{w \theta+w \theta a\left(c^{\prime}(a)-\alpha \theta\right)}{S O C} \frac{\partial \alpha}{\partial x_{W}}$ & $-\frac{R_{a \theta}+w \alpha+w\left(c^{\prime}(a)-\alpha \theta\right) \alpha \theta}{S O C}$ \\
$\ln (w)$ & $\left(c^{\prime}(a)-\alpha \theta\right) \frac{d a}{d x_{W}}$ & $\left(c^{\prime}(a)-\alpha \theta\right) \frac{d a}{d x_{F}}-\theta a \frac{d \alpha}{d x_{F}}$ & $\left(c^{\prime}(a)-\alpha a\right) \frac{d a}{d \theta}-\alpha a$ \\
Worker Utility & $\theta a \frac{\partial \alpha}{\partial x_{W}}$ & 0 & 0 \\
Firm Profits & 0 & $w \theta a \frac{d \alpha}{d x_{F}}$ & $w \alpha a+R_{\theta}$ \\
\hline
\end{tabular}

Note: $S O C=R_{a a}-w\left(c^{\prime}(a)-\alpha \theta\right)^{2}-w c^{\prime \prime}(a)<0$. 
Table III

The Relationship Between Sociability and the Importance of Job Tasks in Current Occupation in the United States (Dependent Variables: Importance of Job Tasks)

\begin{tabular}{|c|c|c|c|c|c|c|c|c|c|c|}
\hline \multirow{3}{*}{ Dependent Variable } & \multirow{3}{*}{$\begin{array}{c}\begin{array}{c}\text { St.Dev. of Dep. } \\
\text { Variable }\end{array} \\
(1) \\
\end{array}$} & \multicolumn{3}{|c|}{ Sociability at Age Six } & \multicolumn{3}{|c|}{ Sociability in Early Adulthood } & \multicolumn{3}{|c|}{ Clubs } \\
\hline & & & & & & & & & & \\
\hline & & (2) & (3) & (4) & $(5)$ & (6) & $(7)$ & $(8)$ & (9) & $(10)$ \\
\hline Interpersonal Interactions & 2.329 & 0.114 & $(0.026)$ & {$[0.045]$} & 0.196 & $(0.035)$ & {$[0.056]$} & 0.050 & $(0.022)$ & {$[0.025]$} \\
\hline Reasoning & 0.898 & 0.019 & $(0.008)$ & {$[0.019]$} & 0.023 & $(0.011)$ & {$[0.017]$} & 0.029 & $(0.007)$ & [0.038] \\
\hline Math & 1.003 & 0.009 & $(0.009)$ & {$[0.008]$} & 0.016 & $(0.013)$ & {$[0.011]$} & 0.020 & $(0.008)$ & {$[0.023]$} \\
\hline Language & 1.116 & 0.026 & $(0.010)$ & {$[0.022]$} & 0.034 & $(0.013)$ & {$[0.020]$} & 0.034 & $(0.008)$ & [0.036] \\
\hline Strength & 0.687 & -0.006 & $(0.008)$ & {$[0.008]$} & -0.023 & $(0.010)$ & {$[0.022]$} & -0.006 & $(0.006)$ & [0.010] \\
\hline Physical Tasks & 0.289 & -0.001 & $(0.003)$ & {$[0.002]$} & -0.011 & $(0.004)$ & {$[0.025]$} & -0.003 & $(0.003)$ & [0.013] \\
\hline Specific Training & 1.594 & 0.037 & $(0.015)$ & {$[0.021]$} & 0.050 & $(0.020)$ & {$[0.021]$} & 0.045 & $(0.012)$ & [0.033] \\
\hline
\end{tabular}

Note: All data taken from the NLSY79, except for the task measures in the current occupation. These are three-digit occupational averages merged from the 1977 Dictionary of Occupational Titles. All regressions are estimated by GLS and control for gender, education, a quadratic in experience, race, Hispanic background, the score on the Armed Forces Qualifying Test, mother's and father's education, and 3 year averages of family size and household income as a child. Standard errors are reported in parentheses. The predicted effects, reported in brackets, give the share of a standard deviation in the dependent variable explained by a one standard deviation change in the sociability variables. The definitions of the variables are provided in the Data Appendix in Table A1 and A2. 
Table IV

The Relationship Between Sociability at Age 16 and the Importance of Job Tasks in Current Occupation at Age 30 in Britain (Dependent Variables: Importance of Job Tasks)

\begin{tabular}{|c|c|c|c|c|c|c|}
\hline \multirow{3}{*}{$\begin{array}{l}\text { Importance of Job } \\
\text { Tasks in Current Job }\end{array}$} & \multirow{3}{*}{$\begin{array}{c}\text { St.Dev. of Dep. } \\
\text { Variable } \\
\text { (1) }\end{array}$} & \multicolumn{5}{|c|}{ Behavioral Indicators at Age 16} \\
\hline & & $\begin{array}{c}\text { Social Behavior } \\
\text { During School Term }\end{array}$ & $\begin{array}{l}\text { Social Behavior } \\
\text { During Holidays }\end{array}$ & $\begin{array}{c}\text { Social Behavior } \\
\text { During Leisure Time }\end{array}$ & $\begin{array}{c}\text { Log of the Number } \\
\text { of Friends }\end{array}$ & $\begin{array}{l}\text { Self Description of } \\
\text { Character: Outgoing }\end{array}$ \\
\hline & & $(2)$ & (3) & $(4)$ & $(5)$ & $(6)$ \\
\hline $\begin{array}{l}\text { Interpersonal } \\
\text { Interactions }\end{array}$ & 0.492 & $0.005(0.001)[0.047]$ & $0.005(0.001)[0.003]$ & $0.006(0.002)[0.043]$ & $0.021(0.012)[0.002]$ & $0.017(0.004)[0.422]$ \\
\hline Math & 0.596 & $-0.000(0.002)[0.001]$ & $0.001(0.002)[0.001]$ & $-0.005(0.002)[0.030]$ & $-0.016(0.018)[0.001]$ & $0.001(0.005)[0.021]$ \\
\hline Reading & 0.484 & $-0.001(0.001)[0.010]$ & $0.001(0.001)[0.001]$ & $0.001(0.001)$ [0.007] & $-0.014(0.011)[0.001]$ & $0.002(0.003)[0.025]$ \\
\hline Writing & 0.590 & $0.001(0.001)[0.008]$ & $0.002(0.001)[0.001]$ & $0.003(0.002)[0.018]$ & $-0.006(0.013)[0.001]$ & $0.006(0.004)[0.042]$ \\
\hline $\begin{array}{l}\text { Physical Strength } \\
\text { and Stamina }\end{array}$ & 0.833 & $0.002(0.002)[0.011]$ & $-0.001(0.002)[0.001]$ & $0.004(0.003)[0.017]$ & $0.052(0.021)[0.006]$ & $-0.001(0.006)[0.088]$ \\
\hline Problem Solving & 0.502 & $-0.001(0.001)[0.009]$ & $0.001(0.001)[0.001]$ & $0.000(0.002)[0.000]$ & $0.005(0.012)[0.000]$ & $-0.003(0.003)[0.024]$ \\
\hline Noticing Mistakes & 0.311 & $-0.001(0.001)[0.015]$ & $-0.000(0.001)[0.000]$ & $-0.001(0.001)[0.011]$ & $-0.007(0.008)[0.000]$ & $-0.003(0.002)[0.118]$ \\
\hline $\begin{array}{l}\text { Planning of } \\
\text { Activities }\end{array}$ & 0.484 & $0.003(0.001)$ [0.029] & $0.005(0.001)[0.003]$ & $0.005(0.002)[0.036]$ & $0.024(0.012)[0.002]$ & $0.011(0.003)[0.076]$ \\
\hline $\begin{array}{l}\text { Knowledge of the } \\
\text { Organization }\end{array}$ & 0.412 & $-0.000(0.001)[0.001]$ & $0.001(0.001)[0.000]$ & $-0.001(0.001)[0.009]$ & $-0.025(0.010)[0.002]$ & $-0.001(0.003)[0.327]$ \\
\hline$n$ & & 3,749 & 3,464 & 3,267 & 3,915 & 3,566 \\
\hline
\end{tabular}

Note: All data taken from the British Cohort Study, except for the task measures in the current occupation. These are occupational averages merged from the British Skills Survey 2001. All regressions are OLS and control for gender, being married and level of education. The predicted effects, in squared brackets, give the share of a standard deviation in the dependent variable explained by a one standard deviation change in the sociability variables. The definitions of the variables are provided in the Data Appendix in Table A1 and A2. 
Table V

The Relationship Between Sociability and Log Wages in the United States and the United Kingdom (Dependent Variable: Log Wages)

\begin{tabular}{|c|c|c|c|c|c|}
\hline \multirow[t]{2}{*}{ United States } & & & Sociability at Age Six & $\begin{array}{c}\text { Sociability in Early } \\
\text { Adulthood }\end{array}$ & $\begin{array}{c}\text { Clubs in High } \\
\text { School } \\
\end{array}$ \\
\hline & & & $(1)$ & $(2)$ & (3) \\
\hline Interpersonal Interactions & & & $(0.003)$ & $(0.005)$ & $\begin{array}{ll}-0.018 \quad(0.002) \\
\end{array}$ \\
\hline Interpersonal Interactions $*$ Sociability & & & $(0.001)$ & $(0.002)$ & $(0.001)$ \\
\hline \multirow[t]{2}{*}{ United Kingdom } & $\begin{array}{c}\text { Social Behavior } \\
\text { During School Term }\end{array}$ & $\begin{array}{l}\text { Social Behavior } \\
\text { During Holidays }\end{array}$ & $\begin{array}{c}\text { Social Behavior } \\
\text { During Leisure Time }\end{array}$ & $\begin{array}{c}\text { Log of the Number } \\
\text { of Friends }\end{array}$ & $\begin{array}{c}\text { Self Description of } \\
\text { Character: } \\
\text { Outgoing } \\
\end{array}$ \\
\hline & (1) & (2) & (3) & (4) & (5) \\
\hline Interpersonal Interactions & $(0.011)$ & $(0.010)$ & $(0.004)$ & $(0.005)$ & $(0.010)$ \\
\hline Interpersonal Interactions * Sociability & $(0.003)$ & $(0.003)$ & $(0.002)$ & $(0.001)$ & $(0.001)$ \\
\hline
\end{tabular}

Note: United States: All data taken from the NLSY79, except for the task measures in the current occupation. These are occupational averages merged from the 1977 Dictionary of Occupational Titles. All regressions are estimated by including individual dummy variables, year dummy variables, education, a quadratic in

experience and occupation random effects. United Kingdom: All data are taken from the BCS, except for the interpersonal interactions data, which are from the BSS All regressions are estimated by including education, a gender dummy, a quadratic in experience, all other tasks from the BSS used in the analysis reported in Table IV and occupation random effects. Standard errors are reported in parentheses. The definitions of the variables are provided in the Data Appendix in Table A1 and A2. 
Table VI

Computerization, Teamwork and Organizational Change Correlated to (Changes in) Interpersonal Interactions

in Britain, Germany and the United States

(Dependent Variable: (Change in) Interpersonal Interactions)

\begin{tabular}{|c|c|c|c|c|c|c|c|c|c|c|c|c|}
\hline \multirow[b]{3}{*}{ Britain } & \multicolumn{4}{|c|}{ Cross-Section } & \multicolumn{4}{|c|}{ Cross-Section } & \multicolumn{4}{|c|}{ Changes } \\
\hline & (1) & (2) & (3) & (4) & (5) & (6) & (7) & (8) & (9) & (10) & (11) & (12) \\
\hline & 1997 & & & & 2001 & & & & Change 1 & 2001 & & \\
\hline Computer Use & $\begin{array}{c}0.895 \\
(0.111)\end{array}$ & & & $\begin{array}{c}0.664 \\
(0.113)\end{array}$ & $\begin{array}{c}0.772 \\
(0.081)\end{array}$ & & & $\begin{array}{c}0.398 \\
(0.181)\end{array}$ & $\begin{array}{c}0.674 \\
(0.135)\end{array}$ & & & $\begin{array}{c}0.474 \\
(0.131)\end{array}$ \\
\hline Team Working & & $\begin{array}{c}0.445 \\
(0.051)\end{array}$ & & $\begin{array}{c}0.363 \\
(0.055)\end{array}$ & & $\begin{array}{c}0.464 \\
(0.047)\end{array}$ & & $\begin{array}{c}0.273 \\
(0.051)\end{array}$ & & $\begin{array}{c}0.311 \\
(0.042)\end{array}$ & & $\begin{array}{c}0.264 \\
(0.044)\end{array}$ \\
\hline Organizational Change & & & $\begin{array}{c}0.476 \\
(0.171)\end{array}$ & $\begin{array}{l}-0.243 \\
(0.162)\end{array}$ & & & $\begin{array}{c}1.215 \\
(0.129)\end{array}$ & $\begin{array}{c}0.694 \\
(0.136)\end{array}$ & & & $\begin{array}{c}0.248 \\
(0.099)\end{array}$ & $\begin{array}{c}0.111 \\
(0.092)\end{array}$ \\
\hline $\begin{array}{l}\mathrm{R}^{2} \\
n\end{array}$ & $\begin{array}{c}0.306 \\
294\end{array}$ & $\begin{array}{c}0.325 \\
294\end{array}$ & $\begin{array}{c}0.171 \\
294\end{array}$ & $\begin{array}{c}0.385 \\
294\end{array}$ & $\begin{array}{c}0.408 \\
324\end{array}$ & $\begin{array}{c}0.459 \\
324\end{array}$ & $\begin{array}{c}0.448 \\
324\end{array}$ & $\begin{array}{c}0.540 \\
324\end{array}$ & $\begin{array}{c}0.178 \\
264\end{array}$ & $\begin{array}{c}0.178 \\
264\end{array}$ & $\begin{array}{c}0.025 \\
264\end{array}$ & $\begin{array}{c}0.220 \\
264\end{array}$ \\
\hline Germany & 1979 & & & & 1998 & & & & Change 1 & 1998 & & \\
\hline Computer Use & $\begin{array}{c}0.528 \\
(0.126)\end{array}$ & & & & $\begin{array}{c}0.501 \\
(0.138)\end{array}$ & & & & $\begin{array}{c}0.119 \\
(0.020)\end{array}$ & & & \\
\hline $\begin{array}{l}\mathrm{R}^{2} \\
n\end{array}$ & $\begin{array}{c}0.085 \\
87\end{array}$ & & & & $\begin{array}{c}0.185 \\
84\end{array}$ & & & & $\begin{array}{c}0.932 \\
338\end{array}$ & & & \\
\hline United States & 1984 & & & & 1993 & & & & Change 1 & 1993 & & \\
\hline Computer Use & $\begin{array}{c}0.429 \\
(0.111)\end{array}$ & & & & $\begin{array}{c}0.600 \\
(0.080)\end{array}$ & & & & $\begin{array}{c}0.150 \\
(0.126)\end{array}$ & & & \\
\hline $\begin{array}{l}\mathrm{R}^{2} \\
n\end{array}$ & $\begin{array}{c}0.089 \\
431\end{array}$ & & & & $\begin{array}{c}0.238 \\
421\end{array}$ & & & & $\begin{array}{c}0.008 \\
391\end{array}$ & & & \\
\hline
\end{tabular}

Note: All regressions are OLS and weighted by occupation size, except for the changes in Germany. These are estimated using a panel regression with time fixed effects and occupation fixed effects. All regressions include unreported covariates to control for education and gender. The inclusion of these covariates does not change the estimation results. The coefficients show the impact on the importance of interpersonal interactions. The regression results on the changes between 1997 and 2001 also use the changes in the independent variables. For Britain the data are taken from the 1997 and 2001 waves of the BSS. For Germany the Data come from the BIBB/IAB Database in 1979 and 1998. For the United States the interpersonal interactions data are taken from the 1977 and 1991 DOT and the information about computerization is taken from the 1984 and 1993 October Supplements to the Current Population Surveys. The data are merged using the same occupational classifications as constructed by Autor, Levy and Murnane [2003]. See the Data Appendix for the exact construction of the variables. 
Table VII

Effect of Skills on Female Employment in Britain, 1997-2001

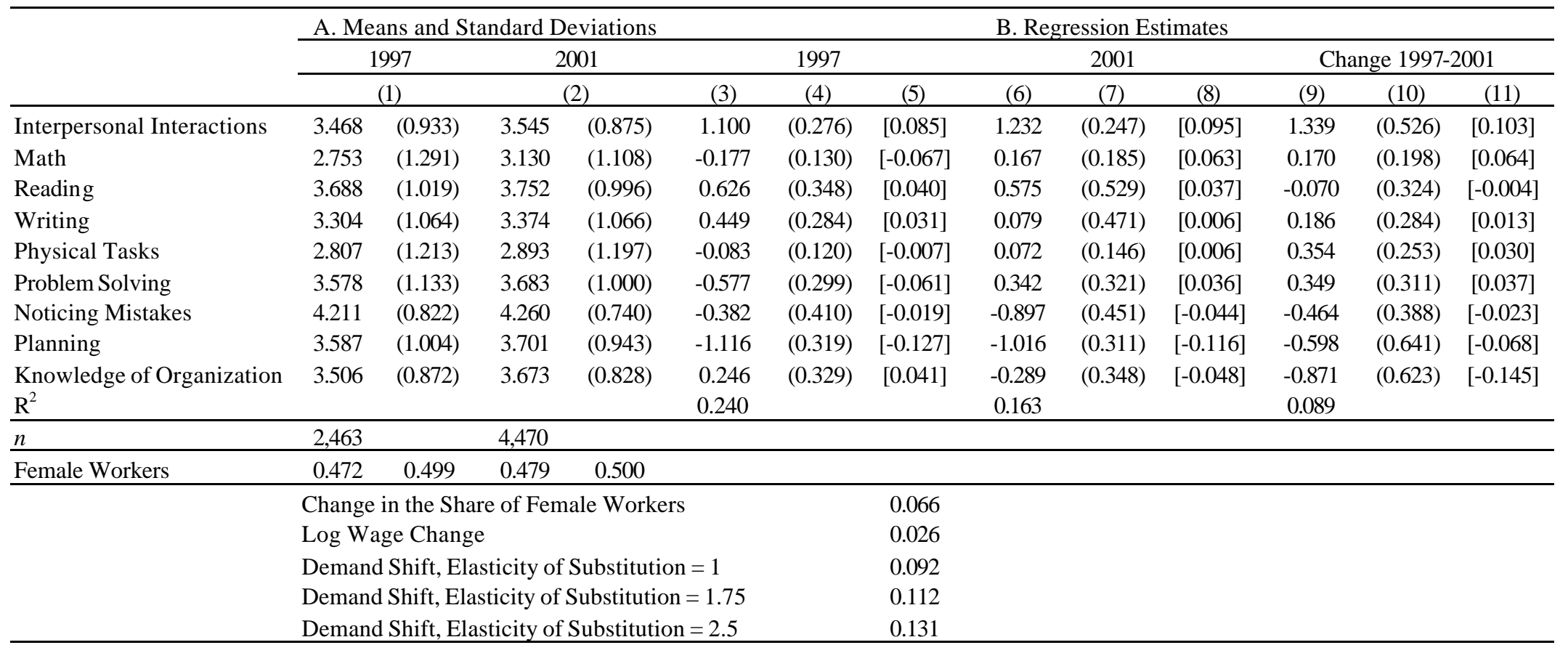

Note: Panel A reports means and standard deviations (in parentheses) of skill variables. Panel B reports effects of skill variables on women's employment share. Observations are three-digit occupations. Numbers in brackets give the standard errors and the numbers in squared brackets the predicted effects of the change in the variable between 1997 and 2001. Regressions estimated by instrumental variables, with the importance of the job tasks instrumented by the importance of the job tasks among men. 
Table VIII

The Effects of Job Tasks on Female Relative Employment in Germany, 1979-1998

\begin{tabular}{|c|c|c|c|c|c|c|c|c|c|c|c|c|c|}
\hline \multirow[b]{4}{*}{ Interpersonal Interactions } & \multicolumn{4}{|c|}{ A. Means, Standard Deviations } & \multicolumn{9}{|c|}{ B. Regression Estimates } \\
\hline & \multirow{2}{*}{\multicolumn{2}{|c|}{$\begin{array}{c}1979 \\
(1)\end{array}$}} & \multirow{2}{*}{\multicolumn{2}{|c|}{$\frac{1998}{(2)}$}} & \multicolumn{3}{|c|}{ GLS - Random Effects } & \multicolumn{3}{|c|}{ Within - Fixed Effects } & \multicolumn{3}{|c|}{ IV, Within - Fixed Effects } \\
\hline & & & & & (3) & (4) & $(5)$ & $(6)$ & (7) & $(8)$ & (9) & $(10)$ & (11) \\
\hline & 0.077 & $(0.058)$ & 0.465 & $(0.164)$ & 1.126 & $(0.136)$ & {$[0.437]$} & 0.715 & $(0.412)$ & {$[0.278]$} & 0.700 & $(0.488)$ & {$[0.272]$} \\
\hline Analytic Skills & 0.043 & $(0.057)$ & 0.160 & $(0.112)$ & -0.089 & $(0.137)$ & {$[-0.010]$} & 0.388 & $(0.431)$ & {$[0.046]$} & 0.372 & $(0.515)$ & [0.044] \\
\hline Routine Cognitive & 0.369 & $(0.253)$ & 0.209 & $(0.200)$ & -0.115 & $(0.041)$ & {$[0.018]$} & -0.079 & $(0.120)$ & {$[0.013]$} & -0.082 & $(0.132)$ & [0.013] \\
\hline Routine Manual & 0.331 & $(0.237)$ & 0.138 & $(0.199)$ & 0.056 & $(0.041)$ & {$[-0.011]$} & 0.058 & $(0.115)$ & {$[-0.011]$} & 0.058 & $(0.118)$ & {$[-0.011]$} \\
\hline Non-Routine Manual & 0.156 & $(0.181)$ & 0.156 & $(0.221)$ & -0.232 & $(0.063)$ & {$[0.000]$} & 0.160 & $(0.208)$ & {$[0.000]$} & 0.160 & $(0.219)$ & {$[0.000]$} \\
\hline $\mathrm{N}$ & 28,337 & & 25,739 & & 306 & & & 306 & & & & & 306 \\
\hline Female Relative Emp. & -1.176 & $(2.203)$ & -0.584 & $(1.708)$ & Chang & Share & 0.592 & & & 0.592 & & & 0.592 \\
\hline Women's Relative Wages & -0.175 & & -0.185 & & & & -0.010 & & & -0.010 & & & -0.010 \\
\hline Change in Demand $\mathrm{e}=1$ & & & & & & & 0.582 & & & 0.582 & & & 0.582 \\
\hline Change in Demand e $=1.75$ & & & & & & & 0.575 & & & 0.575 & & & 0.575 \\
\hline Change in Demand e $=2.5$ & & & & & & & 0.567 & & & 0.567 & & & 0.567 \\
\hline
\end{tabular}

Note: Panel A reports means and standard deviations (in parentheses) of skill variables. Panel B reports effects of skill variables on women's employment share. Observations are two-digit occupations. Numbers in brackets give the predicted effects of the change in the variable between 1979 and 1998 . Instrumental variables regression estimated by instrumenting for the importance of the job tasks by the importance of the job tasks among men. 
Table IX

The Effect of Job Tasks on Female and Black Employment in the United States, 1980-1990

\begin{tabular}{|c|c|c|c|c|c|c|c|c|}
\hline & \multicolumn{4}{|c|}{ Women } & \multicolumn{4}{|c|}{ Blacks } \\
\hline & \multicolumn{2}{|c|}{1980 Cross section } & \multicolumn{2}{|c|}{1980 to 1990 Change } & \multicolumn{2}{|c|}{1980 Cross-Section } & \multicolumn{2}{|c|}{ Changes 1980-1990 } \\
\hline & $(1)$ & (2) & (3) & (4) & $(5)$ & (6) & (7) & (8) \\
\hline Interpersonal Tasks & 0.219 & $(0.046)$ & 0.116 & $(0.062)$ & -0.058 & $(0.015)$ & -0.090 & $(0.040)$ \\
\hline Reasoning & -0.864 & $(0.443)$ & -0.137 & $(0.159)$ & 0.266 & $(0.150)$ & -0.092 & $(0.102)$ \\
\hline Mathematics & -0.214 & $(0.205)$ & -0.028 & $(0.093)$ & -0.549 & $(0.069)$ & -0.079 & $(0.059)$ \\
\hline Language & 2.13 & $(0.272)$ & 0.269 & $(0.095)$ & 0.047 & $(0.092)$ & 0.172 & $(0.061)$ \\
\hline Strength & -0.586 & $(0.169)$ & & & 0.029 & $(0.057)$ & & \\
\hline Physical Tasks & -2.166 & $(0.411)$ & & & 0.169 & $(0.139)$ & & \\
\hline Specific Skills & -0.6 & $(0.121)$ & & & -0.204 & $(0.041)$ & & \\
\hline $\mathrm{R}^{2}$ & 0.499 & & 0.144 & & 0.503 & & 0.119 & \\
\hline \multirow[t]{3}{*}{$n$} & 484 & & 483 & & 482 & & 478 & \\
\hline & \multicolumn{8}{|c|}{ Annual Demand Shift Implied By Change in Interpersonal Skills Based and Estimates (*100) } \\
\hline & In 1977 & In 1992 & In 1977 & In 1992 & In 1977 & In 1992 & In 1977 & In 1992 \\
\hline Between Occupations & 0.241 & -0.197 & 0.127 & -0.104 & -0.064 & 0.052 & -0.099 & 0.081 \\
\hline Total (Between is .5) & 0.482 & -0.395 & 0.255 & -0.208 & -0.128 & 0.105 & -0.198 & 0.162 \\
\hline Total (Between is .28) & 0.861 & -0.705 & 0.455 & -0.372 & -0.321 & 0.262 & -0.495 & 0.405 \\
\hline Total (Between is .1) & 2.411 & -1.973 & 1.273 & -1.041 & -0.642 & 0.525 & -0.990 & 0.810 \\
\hline Total (Between is .05) & 4.822 & -3.945 & 2.545 & -2.083 & -1.283 & 1.050 & -1.979 & 1.619 \\
\hline
\end{tabular}

Note. Lower panel gives the implied effect of breaks in the importance of interpersonal tasks, given by the estimated effect of interpersonal tasks on the employment of women or blacks multiplied by the change in trend increase in the importance of interpersonal tasks in 1982 or 1995 . The total estimates multiple the breaks in the within trends under the assumption that the within trend breaks are the shown share of the total. 
Table X

The Effects of Job Tasks on Employment by Race and Ethnicity in the United States, 1980-1990

\begin{tabular}{|c|c|c|c|c|c|c|c|c|c|}
\hline \multirow{2}{*}{ Panel A: All } & \multicolumn{3}{|c|}{ Blacks } & \multicolumn{3}{|c|}{ Non-Whites, Non-Blacks } & \multicolumn{3}{|c|}{ Hispanics } \\
\hline & (1) & (2) & (3) & (4) & (5) & (6) & (7) & $(8)$ & (9) \\
\hline Interpersonal Tasks & -0.090 & $(0.040)$ & {$[-0.208]$} & -0.044 & $(0.027)$ & {$[-0.103]$} & 0.008 & $(0.055)$ & [0.018] \\
\hline Reasoning & -0.092 & $(0.102)$ & {$[-0.081]$} & -0.186 & $(0.070)$ & {$[-0.163]$} & 0.060 & $(0.141)$ & {$[0.053]$} \\
\hline Mathematics & -0.079 & $(0.059)$ & {$[-0.074]$} & 0.021 & $(0.041)$ & {$[0.020]$} & -0.146 & $(0.082)$ & {$[-0.137]$} \\
\hline Language & 0.172 & $(0.061)$ & {$[0.185]$} & 0.051 & $(0.042)$ & {$[0.054]$} & -0.095 & $(0.085)$ & {$[-0.101]$} \\
\hline $\mathrm{R}^{2}$ & .119 & & & .182 & & & .153 & & \\
\hline$n$ & 478 & & & 477 & & & 463 & & \\
\hline Panel B: Men & \multicolumn{3}{|c|}{ Black Men } & \multicolumn{3}{|c|}{ Non-White, Non-Black Men } & \multicolumn{3}{|c|}{ Hispanic Men } \\
\hline Interpersonal Tasks & -0.204 & $(0.053)$ & {$[-0.471]$} & -0.263 & $(0.045)$ & {$[-0.606]$} & -0.203 & $(0.070)$ & {$[-0.470]$} \\
\hline Reasoning & 0.146 & $(0.134)$ & {$[0.128]$} & -0.186 & $(0.114)$ & {$[-0.163]$} & 0.221 & $(0.178)$ & [0.193] \\
\hline Mathematics & 0.048 & $(0.078)$ & {$[0.045]$} & 0.061 & $(0.067)$ & {$[0.057]$} & -0.054 & (0.103) & {$[-0.050]$} \\
\hline Language & -0.118 & $(0.080)$ & {$[-0.126]$} & 0.110 & $(0.069)$ & {$[0.117]$} & -0.138 & $(0.106)$ & {$[-0.147]$} \\
\hline $\mathrm{R}^{2}$ & 0.048 & & & 0.216 & & & 0.051 & & \\
\hline$n$ & 467 & & & 474 & & & 450 & & \\
\hline
\end{tabular}

Note: Estimates based on changes between 1980 and 1990. Standard errors in parentheses. Predicted effects of a 1 standard deviation change in the variable in brackets. 
Table XI

The Effects of Job Tasks on English Ability and Immigrant Status in the United States, 1980

\begin{tabular}{|c|c|c|c|c|c|c|c|c|c|}
\hline & \multicolumn{3}{|c|}{ Speaks English at Home } & \multicolumn{3}{|c|}{$\begin{array}{c}\text { English Best Category Given Speaks } \\
\text { Other Language at Home }\end{array}$} & \multicolumn{3}{|c|}{$\begin{array}{c}\text { Born Outside United States and Its } \\
\text { Territories }\end{array}$} \\
\hline & $(1)$ & (2) & (3) & (4) & (5) & (6) & (7) & $(8)$ & (9) \\
\hline Interpersonal Tasks & 0.049 & $(0.010)$ & {$[0.114]$} & 0.075 & $(0.011)$ & {$[0.174]$} & -0.037 & $(0.014)$ & {$[-0.084]$} \\
\hline Reasoning & 0.189 & $(0.093)$ & {$[0.165]$} & 0.103 & $(0.104)$ & {$[0.090]$} & -0.295 & $(0.138)$ & {$[-0.259]$} \\
\hline Mathematics & -0.040 & $(0.043)$ & {$[-0.037]$} & 0.017 & $(0.048)$ & {$[0.016]$} & 0.223 & $(0.064)$ & {$[0.208]$} \\
\hline Language & 0.039 & $(0.057)$ & {$[0.042]$} & 0.160 & $(0.064)$ & {$[0.172]$} & -0.147 & $(0.085)$ & {$[-0.158]$} \\
\hline Strength & -0.084 & $(0.035)$ & {$[-0.059]$} & -0.164 & $(0.040)$ & {$[-0.116]$} & 0.060 & $(0.053)$ & {$[0.042]$} \\
\hline Physical Tasks & 0.307 & $(0.086)$ & {$[0.095]$} & 0.185 & $(0.096)$ & {$[0.057]$} & -0.506 & $(0.128)$ & {$[-0.156]$} \\
\hline Specific Skills & 0.003 & $(0.025)$ & {$[0.005]$} & -0.030 & $(0.028)$ & {$[-0.048]$} & 0.030 & $(0.038)$ & {$[0.047]$} \\
\hline $\mathrm{R}^{2}$ & 0.316 & & & 0.746 & & & 0.166 & & \\
\hline$n$ & 485 & & & 476 & & & 485 & & \\
\hline
\end{tabular}

Note: Standard errors in parentheses. Predicted effects of a 1 standard deviation change in the variable in brackets. 
Table A1

Definitions of Interpersonal Interactions in the United States, Germany, and Britain

\begin{tabular}{|c|c|c|c|c|c|}
\hline Country & Data Source & Definition of Interpersonal Tasks & Variable Construction & \multicolumn{2}{|c|}{$\begin{array}{c}\text { Mean } \\
\text { (Standard Deviation) } \\
\text { [Year] }\end{array}$} \\
\hline $\begin{array}{l}\text { United } \\
\text { States }\end{array}$ & $\begin{array}{l}\text { Dictionary of Occupational } \\
\text { Titles Fourth [1977] and } \\
\text { Revised Fourth Edition [1991] }\end{array}$ & $\begin{array}{l}\text { We use three variables from the DOT } \\
\text { temperaments: (i) adaptability to situations } \\
\text { involving the interpretation of feelings, ideas or } \\
\text { facts in terms of personal viewpoint, (ii) } \\
\text { adaptability to influencing people in their } \\
\text { opinions, attitudes or judgments about ideas or } \\
\text { things, and (iii) adaptability to dealing with } \\
\text { people beyond giving and receiving instructions. } \\
\text { Two variables from DOT interest factors to } \\
\text { signify interests, tastes and preferences for } \\
\text { certain kinds of activities that are entailed in job } \\
\text { performance: (i) a preference for activities } \\
\text { involving business contact with people, and (ii) a } \\
\text { preference for working for the presumed good of } \\
\text { people. }\end{array}$ & $\begin{array}{l}\text { The presence or absence of } \\
\text { a given temperament, rather } \\
\text { than the level or degree } \\
\text { required, is indicated. } \\
\text { Temperaments are coded } 0 \\
\text { or } 1 \text {. The interests equal }-1 \text {, } \\
0 \text {, or } 1 \text {. In constructing the } \\
\text { measures we took the mean } \\
\text { of the sum of the } \\
\text { occupation score on these } \\
\text { items. }\end{array}$ & $\begin{array}{l}.9274 \\
\text { [DOT' } 77 \text { in } \\
1977 \text { ] } \\
.9408 \\
\text { [DOT' } 91 \text { in } \\
\text { 1977] }\end{array}$ & $\begin{array}{l}1.1499 \\
\text { [DOT' } 77 \text { in } \\
1991] \\
1.1788 \\
\text { [DOT' } 91 \text { in } \\
1991]\end{array}$ \\
\hline Germany & $\begin{array}{l}\text { Bundesinstitut für } \\
\text { Berufsbildung (BIBB) and } \\
\text { Institut für Arbeitsmarkt- und } \\
\text { Berufsforschung der } \\
\text { Bundesanstalt für Arbeit (IAB) } \\
{[1979,1985,1991, \text { and 1998] }} \\
\end{array}$ & $\begin{array}{l}\text { We use variables for whether the job involves } \\
\text { negotiating, lobbying, coordinating and } \\
\text { organizing; teaching or training; selling, buying, } \\
\text { advising, or advertising; entertaining or } \\
\text { presenting; serving and accommodating; and } \\
\text { helping others }\end{array}$ & $\begin{array}{l}\text { The variables are coded } 0 \text { or } \\
1 . \text { We average across the } \\
\text { responses to the questions } \\
\text { and multiply by } 100\end{array}$ & $\begin{array}{c}9.272 \\
(15.516) \\
{[1979]}\end{array}$ & $\begin{array}{c}21.624 \\
(31.087) \\
{[1998]}\end{array}$ \\
\hline Britain & $\begin{array}{l}\text { First [1997] and Second [2001] } \\
\text { British Skills Survey }\end{array}$ & $\begin{array}{l}\text { We use variables for the importance of dealing } \\
\text { with people; working with a team of people; } \\
\text { instructing, training or teaching people; making } \\
\text { speeches or presentations; persuading or } \\
\text { influencing others; selling a product; counseling, } \\
\text { advising or caring for customers or clients; and } \\
\text { listening carefully to colleagues }\end{array}$ & $\begin{array}{l}\text { The } \mathrm{v} \text { ariables range from } 1 \\
\text { (not important) to } 5 \\
\text { (essential). We average } \\
\text { across the responses to the } \\
\text { various questions.. }\end{array}$ & $\begin{array}{c}3.468 \\
(0.933) \\
{[1997]}\end{array}$ & $\begin{array}{c}3.554 \\
(0.875) \\
{[2001]}\end{array}$ \\
\hline
\end{tabular}


Table A2

Definitions of Sociability in the United States, and Britain

\begin{tabular}{|c|c|c|c|c|}
\hline \multirow[t]{2}{*}{ Country } & \multicolumn{2}{|r|}{ Sociability Variables } & \multirow[t]{2}{*}{ Variable Construction } & \multirow{2}{*}{$\begin{array}{c}\text { Mean } \\
\text { (Standard Deviation) }\end{array}$} \\
\hline & Measure & Definition & & \\
\hline \multirow[t]{3}{*}{$\begin{array}{l}\text { United } \\
\text { States }\end{array}$} & Clubs & $\begin{array}{l}\text { Respondents were shown cards with } 9 \text { types of high school clubs and } \\
\text { asked how many of them they participated in during high school. }\end{array}$ & $\begin{array}{l}\text { The sum of the number } \\
\text { of different types of } \\
\text { clubs is used. }\end{array}$ & $\begin{array}{c}1.970 \\
(1.183)\end{array}$ \\
\hline & $\begin{array}{l}\text { Sociability at } \\
\text { age } 6\end{array}$ & $\begin{array}{l}\text { Respondents were asked, "Thinking of yourself when you were } 6 \text { years } \\
\text { old, would you describe yourself as: (1) extremely shy; (2) somewhat shy; } \\
\text { (3) somewhat outgoing; or (4) extremely outgoing?" }\end{array}$ & $\begin{array}{l}\text { The responses are } \\
\text { used. }\end{array}$ & $\begin{array}{l}2.421 \\
(0.912)\end{array}$ \\
\hline & $\begin{array}{l}\text { Sociability in } \\
\text { adulthood }\end{array}$ & $\begin{array}{l}\text { Respondents were asked, "Thinking of yourself as an adult, would you } \\
\text { describe yourself as: (1) extremely shy; (2) somewhat shy; (3) somewhat } \\
\text { outgoing; or (4) extremely outgoing?" }\end{array}$ & $\begin{array}{l}\text { The responses are } \\
\text { used. }\end{array}$ & $\begin{array}{c}2.949 \\
(0.663)\end{array}$ \\
\hline \multirow{5}{*}{ Britain } & $\begin{array}{l}\text { Social behavior } \\
\text { during school } \\
\text { term }\end{array}$ & $\begin{array}{l}\text { Stay at home with boy/girlfriend; Stay at home of boy/girlfriend; Go to the } \\
\text { cinema etc. with boy/girlfriend; Stay at home with other friends; Spend time } \\
\text { at the homes of other friends; Go with friends to cinema, disco etc.; and Go } \\
\text { out with friends do nothing special }\end{array}$ & $\begin{array}{l}\text { The questions asked } \\
\text { are whether you are } \\
\text { engaged in the social } \\
\text { activities listed. The }\end{array}$ & $\begin{array}{l}8.764 \\
(4.657)\end{array}$ \\
\hline & $\begin{array}{l}\text { Social behavior } \\
\text { during holidays }\end{array}$ & $\begin{array}{l}\text { Stay at home by yourself or with family; Go out by myself or with family; } \\
\text { Go to a friend's house; Have friends round to my house; Go to a youth } \\
\text { club/organization; Go out with brothers/sisters; Do community/volunteer } \\
\text { work; Go to a meeting/political club; Go out with my boy/girlfriend; and Go } \\
\text { out with friends }\end{array}$ & $\begin{array}{l}\text { responses range from } 0 \\
\text { to } 5 \text {. We construct } \\
\text { dummy variables equal } \\
\text { to } 1 \text { if the response is } 1 \text { - } \\
5 \text {. For the number of }\end{array}$ & $\begin{array}{l}10.574 \\
(5.361)\end{array}$ \\
\hline & $\begin{array}{l}\text { Social behavior } \\
\text { during leisure } \\
\text { time }\end{array}$ & $\begin{array}{l}\text { Go to a friend's house; Have friends round to my house; Go to a youth } \\
\text { club/organization; Go out with brothers/sisters; Do community/volunteer } \\
\text { work; Go to a meeting/political club; Go out with my boy/girlfriend; and Go } \\
\text { out with friends }\end{array}$ & $\begin{array}{l}\text { friends we just use the } \\
\text { absolute number of } \\
\text { friends, including } \\
\text { whether the person has }\end{array}$ & $\begin{array}{l}17.023 \\
(4.048)\end{array}$ \\
\hline & $\begin{array}{l}\text { Number of } \\
\text { friends }\end{array}$ & $\begin{array}{l}\text { Boy or Girlfriend; Number of best friends; Number of friends in school; and } \\
\text { Number of friends outside school }\end{array}$ & a boy/girlfriend. & $\begin{array}{l}11.780 \\
(5.482)\end{array}$ \\
\hline & $\begin{array}{l}\text { Self description } \\
\text { of character: } \\
\text { outgoing }\end{array}$ & $\begin{array}{l}\text { We average responses to whether the person is Friendly; Loving; } \\
\text { Outgoing; Shy (entered in reverse); and Quiet (entered in reverse). The } \\
\text { respondents are asked to react to the statement: "I am ...". The response } \\
\text { categories are (1) does not apply; (2) applies somewhat; (3) applies very } \\
\text { much. }\end{array}$ & & $\begin{array}{l}2.542 \\
(1.816)\end{array}$ \\
\hline
\end{tabular}

Note: The data source for the United States is the NLSY79 and for Britain the BCS. 
Table A3

25 Largest Occupations in 1980 Census Sorted by Interpersonal Interactions in the United States

\begin{tabular}{|c|c|c|c|c|c|c|c|}
\hline $\begin{array}{l}\text { Interpersonal } \\
\text { Interactions }\end{array}$ & Reasoning & Math & Language & Strength & Physical & $\begin{array}{c}\text { Specific } \\
\text { Vocational } \\
\text { Training }\end{array}$ & Occupation \\
\hline 4.842 & 3.920 & 2.986 & 3.833 & 1.829 & 0.011 & 5.056 & Sales representatives mining manufacturing and wholesale \\
\hline 4.375 & 3.553 & 2.927 & 3.137 & 1.944 & 0.057 & 3.804 & Sales workers other commodities \\
\hline 3.880 & 4.985 & 3.045 & 4.962 & 1.944 & 0.009 & 6.130 & Teachers elementary school \\
\hline 3.602 & 2.918 & 1.993 & 2.237 & 2.004 & 0.016 & 3.011 & Waiters and waitresses \\
\hline 3.570 & 3.997 & 2.925 & 3.976 & 1.007 & 0.003 & 6.001 & Secretaries \\
\hline 3.525 & 3.259 & 2.262 & 2.574 & 3.025 & 0.764 & 4.251 & Nursing aides orderlies and attendants \\
\hline 2.929 & 4.343 & 3.734 & 3.753 & 1.347 & 0.060 & 6.999 & Supervisors and proprietors sales occupations \\
\hline 2.884 & 4.330 & 3.769 & 3.818 & 1.367 & 0.049 & 7.011 & Managers and administrators n.e.c. \\
\hline 2.654 & 3.137 & 2.470 & 2.178 & 2.000 & 0.009 & 3.003 & Cashiers \\
\hline 2.225 & 3.682 & 2.728 & 3.419 & 1.304 & 0.019 & 4.643 & General office clerks \\
\hline 1.955 & 4.919 & 3.922 & 4.904 & 2.814 & 0.025 & 6.881 & Registered nurses \\
\hline 0.960 & 4.067 & 3.138 & 3.282 & 1.641 & 0.131 & 6.905 & Supervisors production occupations \\
\hline 0.167 & 2.293 & 1.860 & 1.745 & 2.869 & 0.362 & 2.637 & Laborers except construction \\
\hline 0.167 & 2.293 & 1.860 & 1.745 & 2.869 & 0.362 & 2.637 & Stock handlers and baggers \\
\hline-0.395 & 2.956 & 1.809 & 2.126 & 1.900 & 0.516 & 3.455 & Truck drivers light \\
\hline-0.395 & 2.956 & 1.809 & 2.126 & 1.900 & 0.516 & 3.455 & Truck drivers heavy \\
\hline-0.578 & 2.418 & 1.795 & 2.173 & 3.143 & 0.870 & 3.452 & Janitors and cleaners \\
\hline-0.925 & 2.554 & 1.590 & 1.904 & 1.997 & 0.171 & 3.318 & Assemblers \\
\hline-0.925 & 4.000 & 3.703 & 3.073 & 1.018 & 0.005 & 4.834 & Bookkeeping accounting and auditing clerks \\
\hline-1.117 & 3.484 & 2.527 & 2.651 & 2.909 & 0.146 & 5.929 & Short-order cooks \\
\hline-1.296 & 3.265 & 2.368 & 2.387 & 2.088 & 0.475 & 5.454 & Machine operators n.s. \\
\hline-1.577 & 3.887 & 2.915 & 2.956 & 2.870 & 0.883 & 6.750 & Automobile mechanics except apprentices \\
\hline-1.661 & 3.924 & 3.010 & 2.880 & 2.956 & 0.932 & 6.849 & Carpenters except apprentices \\
\hline-1.953 & 4.806 & 4.611 & 4.642 & 0.969 & 0.002 & 7.268 & Accountants and auditors \\
\hline-2.597 & 3.844 & 3.654 & 3.684 & 3.242 & 0.803 & 6.625 & Farmers except horticultural \\
\hline
\end{tabular}


Table A4

10 Largest Occupations in 1979 and 1991 BIBB/IAB by Interpersonal Interactions in Germany

\begin{tabular}{|c|c|c|c|c|c|c|c|}
\hline \multicolumn{8}{|c|}{10 Largest Occupations in 1979} \\
\hline \multicolumn{4}{|c|}{ Ranked According to the Importance of Interpersonal Tasks in 1979} & \multicolumn{4}{|c|}{ Ranked According to the Importance of Interpersonal Tasks in 1991} \\
\hline 1979 & 1991 & $\%$ Change & Occupation & 1979 & 1991 & $\%$ Change & Occupation \\
\hline 0.290 & 0.310 & 0.069 & Registered Nurses and care takers & 0.290 & 0.310 & 0.069 & Registered Nurses and care takers \\
\hline 0.220 & 0.260 & 0.182 & Teachers & 0.190 & 0.260 & 0.368 & Organizers and entrepreneurial occupations \\
\hline 0.190 & 0.260 & 0.368 & Organizers and entrepreneurial occupations & 0.220 & 0.260 & 0.182 & Teachers \\
\hline 0.160 & 0.210 & 0.313 & Sales persons (goods) & 0.140 & 0.250 & 0.786 & Health occupations \\
\hline 0.140 & 0.250 & 0.786 & Health occupations & 0.120 & 0.210 & 0.750 & Secretaries \\
\hline 0.130 & 0.160 & 0.231 & Engineers (chemical, physics, and math) & 0.160 & 0.210 & 0.313 & Sales persons (goods) \\
\hline 0.120 & 0.210 & 0.750 & Secretaries & 0.090 & 0.190 & 1.111 & Sales persons (bank services and insurance) \\
\hline 0.100 & 0.120 & 0.200 & Engineers (technical) & 0.090 & 0.170 & 0.889 & Security persons \\
\hline 0.090 & 0.190 & 1.111 & Sales persons (bank services and insurance) & 0.130 & 0.160 & 0.231 & Engineers (chemical, physics, and math) \\
\hline 0.090 & 0.170 & 0.889 & Security persons & 0.100 & 0.120 & 0.200 & Engineers (technical) \\
\hline \multicolumn{8}{|c|}{ 10 Largest Occupations in 1991} \\
\hline \multicolumn{4}{|c|}{ Ranked According to the Importance of Interpersonal Tasks in 1979} & \multicolumn{4}{|c|}{ Ranked According to the Importance of Interpersonal Tasks in 1991} \\
\hline 0.220 & 0.260 & 0.182 & Teachers & 0.220 & 0.260 & 0.182 & Teachers \\
\hline 0.160 & 0.210 & 0.313 & Sales persons (goods) & 0.140 & 0.250 & 0.786 & Registered Nurses and care takers \\
\hline 0.140 & 0.250 & 0.786 & Registered Nurses and care takers & 0.160 & 0.210 & 0.313 & Sales persons (goods) \\
\hline 0.130 & 0.160 & 0.231 & Engineers (chemical, physics, and math) & 0.130 & 0.160 & 0.231 & Engineers (chemical, physics, and math) \\
\hline 0.100 & 0.120 & 0.200 & Engineers (technical) & 0.100 & 0.120 & 0.200 & Engineers (technical) \\
\hline 0.060 & 0.100 & 0.667 & Secretaries & 0.060 & 0.100 & 0.667 & Secretaries \\
\hline 0.050 & 0.060 & 0.200 & Laborers except construction & 0.040 & 0.100 & 1.500 & Cash operators and book keepers \\
\hline 0.040 & 0.100 & 1.500 & Cash operators and book keepers & 0.050 & 0.060 & 0.200 & Laborers except construction \\
\hline 0.020 & 0.040 & 1.000 & Truck drivers & 0.020 & 0.040 & 1.000 & Truck drivers \\
\hline 0.020 & 0.020 & 0.000 & Machine operators n.s. & 0.020 & 0.020 & 0.000 & Machine operators n.s. \\
\hline
\end{tabular}


Table A5

10 Occupations with largest Increases and Decreases in Interpersonal Interactions in Germany, 1979-1991

\begin{tabular}{clrl}
\hline \% Change & \multicolumn{1}{l}{ 10 Occupations with largest increase in interpersonal interactions } & \% Change & 10 Occupations with largest decrease in interpersonal interactions \\
\hline 0.667 & Secretaries & -0.116 & House Painters \\
0.786 & Registered Nurses and care takers & -0.164 & Glassblowers \\
0.889 & Security persons & -0.248 & Bricklayers \\
0.892 & Doctors & -0.254 & Moving men \\
1.000 & Truck Drivers & -0.257 & Technicians \\
1.111 & Sales persons (bank services and insurance) & -0.414 & Cleaners \\
1.258 & Hair dressers & -0.535 & Potters \\
1.357 & Musicians & -0.561 & Paper constructors \\
1.500 & Cash operators and book keepers & -0.625 & Rollers \\
1.940 & Entrepreneurs & -0.899 & Tailors \\
\hline
\end{tabular}

